\title{
Identification Key for Aspergillus Species Isolated from Maize and Soil of Nandi County, Kenya
}

\author{
Beatrice Wabusya Nyongesa*, Sheila Okoth, Vincent Ayugi \\ School of Biological Sciences, University of Nairobi, Nairobi, Kenya \\ Email: bmutele@yahoo.com, dorisokoth@yahoo.com, vayugi811@gmail.com
}

Received 27 January 2015; accepted 27 March 2015; published 1 April 2015

Copyright (C) 2015 by authors and Scientific Research Publishing Inc.

This work is licensed under the Creative Commons Attribution International License (CC BY). http://creativecommons.org/licenses/by/4.0/

(c) (i) Open Access

\section{Abstract}

The aim of this study was to identify Aspergillus species isolated from maize kernels and soils of maize fields of Nandi County using macro and micro morphological characteristics. A cross sectional research design was used in the study and purposive sampling was employed to determine districts of Nandi County and sub locations where sampling was done. This study was part of a larger project whose aim was to survey aflatoxin exposure in the maize value chain. Aspergillus species were isolated from maize and soil samples using quarter strength potato dextrose agar and modified Rose Bengal agar respectively. Pure cultures of the isolates were sub cultured and transferred onto differential media; malt extract agar, czapek yeast extract agar and czapek dox agar for species identification using macro morphological characteristics. Fungal slides were prepared from pure cultures on potato dextrose agar media after three days to identify micro morphological characteristics. Based on morphological characteristics, seven sections of Aspergillus namely: Flavi, Fumigati, Nigri, Circumdati, Clavati, Nidulantes and Candidi were identified. Aspergillus section Flavi was the most predominant with $57 \%$ followed by section Nigri with $27 \%$ from maize and $58 \%$ of section Flavi followed by $26 \%$ of section Nigri from the soil across the three locations. Aspergillus sections Nidulantes and Candidi were rare and only recovered from the soil samples of Kaptumo location. All the Aspergillius flavus that formed sclerotia both from the soils or maize kernels were of the $L$ strains. In conclusion Aspergillus section Flavi was most frequent during the isolation process and dominated with Aspergillus flavus from both the maize and soil. Morphological characteristics remain the primary tool for detection and identification of Aspergillus species. The significance for high incidence of Aspergillus section Flavi is in regard to their aflatoxin production profiles that poses a health threat to the community and it is of public health concern. Morphological characteristics as a primary tool for Aspergillus identification should be embraced and more personnel with the knowledge are required since modern and faster techniques are scarce and expensive.

\footnotetext{
*Corresponding author.
} 


\section{Keywords}

\section{Aspergillus, Morphological Keys, Maize, Soil, Nandi, Kenya}

\section{Introduction}

Aspergilli are cosmopolitan group of moulds first described by Pier Antonio [1]. Members of the genus Aspergillus are highly aerobic growing on carbon rich substrates with monosaccharide and polysaccharides. Identification of Aspergillus has been based on morphological characteristics of the cultures and the micro characteristics [2] that have provided a broad concept of the species. Despite the rapid availability of molecular methods that are improving the identification of Aspergillus, morphological method has remained the most common tool that is being used and essential for Aspergillus identification [3].

The genus Aspergillus belongs to a group of filamentous Deutromycetes [4] which lacks sexual reproductive phase or is neither known nor discovered. They are characterized by having a spore bearing structure called the conidia head, a basal foot referred to a "foot cell" but not septated. The foot cell has more or less perpendicular hyphae and the conidiophore stipe that terminates into a vesicle. The vesicle may have either one or two layers of synchronised cells and asexually formed spores known as conidia produced by the phialides. Aspergillus conidia head can either be uniseriate or biseriate [5].

Macro and micro morphological characteristics of the genus Aspergillus together with the available taxonomic keys have been used on differential media [6] [7]. The macro morphological features included colony colour and texture, presence of exudates, and production of soluble pigments by the fungi in the media, formations of sclerotia, cleisthethocia and reverse colour of the plate. The micro morphological characteristics that have been used to identify Aspergillus species include, shape of conidia head, seriation, vesicle shape and diameter, stipe; length, width, texture and colour, conidia size, shape, texture and colour; size of sclerotia for those that formed sclerotia.

The genus has been classified into sections based on; seriation either uniseriate, biseriate or both, the shape of conidia head; globose, radiate, columnar or clavate [8]. According to [9] Aspergillus species have varying morphologies and growth responses on different media. Although the method commonly used does not provide evolutionary divergence and reproductive isolation. Morphological methods have been supplemented by molecular and immunological approaches [2] in the diagnosis of Aspergillus and other mycoses. These advanced technologies are not fully realized in many areas. Culture and microscopy are primary laboratory tools available for detecting Aspergillus despite of the improved and more readily available molecular techniques.The objective of the study was to identify Aspergillus species isolated from maize kernels and soils of maize fields of Nandi County using macroscopic and microscopic morphological characteristics.

\section{Materials and Methods}

\subsection{Description of the Study Site}

The study was conducted in Nandi County, one of the administrative Counties of Kenya. The larger Nandi was subdivided into four districts namely North, South, Central and East Nandi. The County has a population size of 631,357 people, 316,363 males and 314,994 females [10].

Nandi lies within latitudes $0^{\circ}$ and $0^{\circ} 34^{\prime \prime}$ North and longitude $34^{\circ} 44^{\prime \prime}$ and $35^{\circ} 25^{\prime \prime}$ East covering an area of 2873 $\mathrm{km}^{2}$ [10]. The highest parts are $1500 \mathrm{~m}$ while the lowest stand at $1300 \mathrm{~m}$ above sea level. It has bimodal rainfall pattern, long rains received between the months of March to June while short rainfall months are in September to November. The average temperature is $20^{\circ} \mathrm{C}$ with the highest being recorded in the months of December to January $\left(23^{\circ} \mathrm{C}\right)$ and the lowest of $12^{\circ} \mathrm{C}$ in the months of July to August [10].

\subsection{Sample Collection}

\subsubsection{Maize Kernel}

Five hundred grams of maize kernels were taken from the storage facilities and placed in sterile paper bags sealed before storing at $4^{\circ} \mathrm{C}$. Maize stored in sacks were sampled from different parts using a closed spear driven 
through to the top and sides to obtain a total of $500 \mathrm{~g}$ of incremental samples [11]. Within the households where there were less than 10 sacks, all were sampled, and over ten to a hundred sacks, only ten sacks were randomly sampled [12]. A total of 236 samples were collected.

\subsubsection{Soil Sampling}

The intermittent pattern was followed across the maize farms to get to points where the soil samples were taken using a trowel. Nine meters were measured from one of the corners diagonally and this was the first point where top soil, up to $4 \mathrm{~cm}$ deep was collected. Another nine meters horizontally and nine vertically a second sample was taken. This continued till 20 sub samples that gave a composite soil sample of between $50-60 \mathrm{~g}$ was collected in sterile $1 \mathrm{~kg}$ brown paper bags, sealed and stored at room temperature $\left(22^{\circ} \mathrm{C}-26^{\circ} \mathrm{C}\right)$ before analysis. The trowel was cleaned with sodium hypochlorite in between the households and left to dry.

\subsection{Isolation and Identification of Moulds}

Selective media were used in the isolation of Aspergillus species from soil and maize kernel samples. The composition of the media used in the cultivation of the fungi is given in Appendix 1.

\subsubsection{Aspergillus Species from the Soil}

In a $7 \mathrm{~mL}$ sterile polystyrene tube, $1 \mathrm{~g}$ of soil was suspended in $3 \mathrm{~mL}$ sterile of $0.05 \%$ Tap Water and mixed for 20 minutes on a Roto-Shaker before plating $1 \mathrm{~mL}$ on modified Rose Bengal agar (MRBA) at $4^{-2}$ and $4^{-3}$ dilutions [13]. One mililitre of each dilution was poured into each of the two plates for every dilution and swirled to cover the bottom of the plate. The plates were incubated in the dark for 3 days at $31^{\circ} \mathrm{C}$. Aspergillus colonies were identified by colony morphology and morphological keys described by [14]. Colonies of Aspergillus were sub cultured onto Aspergillus flavus parasiticus agar as described by [15], and incubated in the dark at $28^{\circ} \mathrm{C}$ for 42 - 72 hours to confirm Apergillus section Flavi by colony reverse colour.

\subsubsection{Aspergillus Species from Maize Kernels}

Five maize kernels were surface sterilized for $1 \mathrm{~min}$ in $2.5 \% \mathrm{NaOCl}$, washed in three changes of sterile distilled water and plated on 1/4 strength potato dextrose agar (PDA) amended with $2 \mathrm{~mL}$ lactic acid to suppress bacterial contamination. Four replicates from each household were plated. Plated kernels were incubated at $31^{\circ} \mathrm{C}$ for three days. Fungal growth colonies on maize kernels were visualized using stereo-binocular microscope (Magnus M24), counted and identified to genus level according to the following authorities: Fusarium spp. according to [16]; Aspergillus spp., Penicillium spp., and other fungi according [17]. Representative isolates of the fungal species were single spored to obtain pure cultures. Pure cultures of Aspergillus species were subcultured on the three differential media, Malt Extract Agar (MEA), Czapek Extract Yeast Agar (CYA) and Czapek Dox Agar (CZ) and incubated $25^{\circ} \mathrm{C}$ for seven days for diameter measurements and identification [7] [8]. This was to study macro and micro morphological characteristics for identification to species level together with taxonomic keys by [6]. To confirm Apergillus section Flavi by colony reverse colour the isolates were subcultured and transferred to Aspergillus flavus parasiticus agar (AFPA) as described by [18], and incubated in the dark at $28^{\circ} \mathrm{C}$ for 42 to 72 hours. Members of section Flavi that never formed sclerotia were subcultured on V-8 juice agar to determine the strain.

\section{Results}

\subsection{Frequency of Fungal Contamination in Maize}

The result from the study revealed four fungal genera. Identification based on morphological characteristics namely Aspergillus, Fusarium, Penicillium and Trichoderma. Apergillus was predominant with a recovery of $70 \%$ and $67 \%$ from maize and soil samples respectively. Five sections of Aspergillus; section Flavi, section Nigri, section Fumigati, section Circumdati and section Clavati were identified from both maize and soil samples. In addition to the sections above two more sections; section Nidulantes and section Candidi were identified from the soil samples of Kaptumo location although they were rare. Aspergillus section Flavi was predominant followed by section Nigri from both maize and soil samples. 


\subsection{Morphological Characteristics of Aspergillus Species}

The colour of the colonies was used for first identification of the sections. Yellow green, green, deep green colours were either for sections Flavi, Fumigati or Nidulantes. Aspergillus sections Nigri were identified by the colonies in shades of black and brown. The white colonies belonged to members of Aspergillus section Candidi. Colonies bluish grey and long hyphal threads with conspicuous club shaped conidia belonged to Aspergillus section Clavati. Members of Aspergillus section Circumdati had cinnamon to ochre appearance. Other features included presence of sclerotia, production of exudates and soluble pigments in the media. Isolates belonging to Aspergillus section Flavi had a bright orange colour on the reverse of the plate on AFPA media.

Members of the various sections were delineated to species level using micro morphological characteristics. These included shapes of conidia head; either globose, radiate, columnar or clavate. Seriation; some species were exclusively biseriate such as Aspergillus section Circumdati and Nidulantes or uniseriate for example section Fumigati and Clavati while others had both; these were section Flavi, Nigri and Candidi. The vesicle; shape and diameter were unique to different Aspergillus species within the sections. The length, width, texture and colour of the conidiophores and conidia; size, diameter, texture and colour. Other micro morphological features used were the shapes of the conidiophores as it grows towards the vesicle, size of the conidia heads and the arrangement of the phialides onto the metulae.

\subsubsection{Aspergillus Section Flavi}

Aspergillus section Flavi had the highest frequency of (133/134) from maize and soils of the total Aspergillus species. Three species were identified namely Aspergillus flavus, A. parasiticus and A. tamarii colonies that have been shown in Figures 1-4.

\section{1) Aspergillus flavus (60631 BM 1 green)}

Colony diameters after 7 days of incubation at $25^{\circ} \mathrm{C}$; MEA 50 - $55 \mathrm{~mm}$; CYA 55 - $60 \mathrm{~mm}$; CZ 35 - $40 \mathrm{~mm}$; On MEA the colonies were yellow green with white mycelia at the edges; formed sporulation rings; the conidia were rough; did not produce exudates and soluble pigments; Reverse colour was cinnamon brown. Colonies on CYA were yellow at the centre with white mycelia at the edge; conidia were rough; lacked exudates and soluble pigments. Reverse colour was straw as shown in Figure 1. The colonies on CZ were white to yellow with scattered conidia, had fluccose texture; no exudates and soluble pigments. Reverse colour was yellow to cream.

Predominantly the species were uniseriate but some were biseriate; conidia heads were radiate to columnar with loosely packed phialides; vesicle diameter and shape; 18 - $36 \mu \mathrm{m}$; radiate. The uniseriate conidia heads had radiate vesicle with the philiades covering upto three quarter of the vesicle; while biseriates the vesicles were spherical to globose with a diameter of (14) 18 - 39 (40) $\mu \mathrm{m}$. The stipes measured $(450-760) \times(9-16) \mu \mathrm{m}$ with

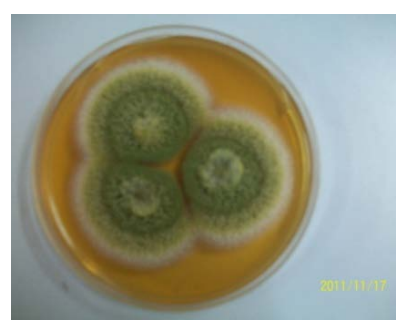

(a)

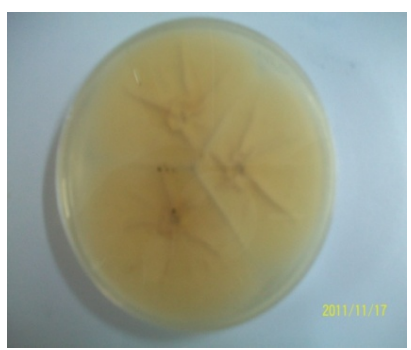

(e)

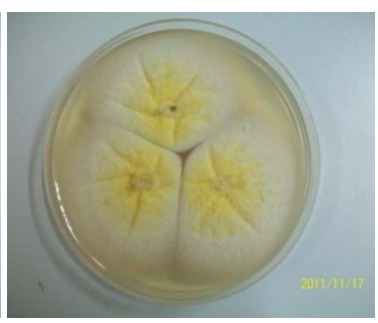

(b)

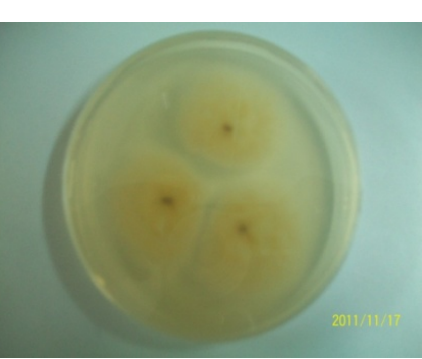

(f)

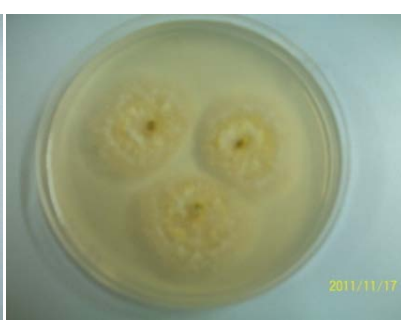

(c)

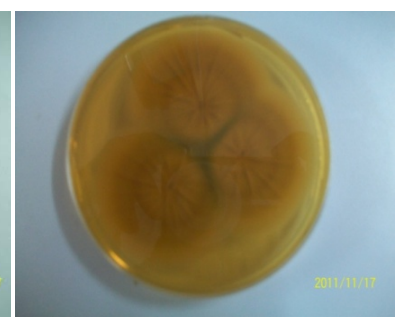

(d)

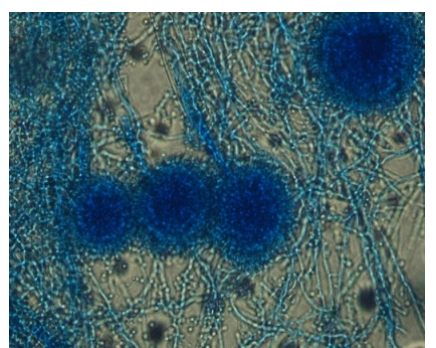

(g)

Figure 1. Aspergillus flavus colonies on; MEA (a \& d); CYA (b \& e); CZ (c \& f); (g) biseriate conidia heads. 
rough texture and colourless. Conidia size range was between 3.5 - $5 \mu \mathrm{m}$; globose; smooth to finely rough and yellow green colour as shown in Figure 1. Diagnostic features; Colonies were yellow green with finely roughened conidia.

\section{2) Aspergillus parasiticus A (40019 BM 16 green)}

Colony diameter after 7 days at $25^{\circ} \mathrm{C}$; PDA 20 - $30 \mathrm{~mm}$; MEA 15 - $20 \mathrm{~mm}$; CYA 50 - $60 \mathrm{~mm}$; CZ 20 - $25 \mathrm{~mm}$. On PDA the colonies were green with white mycelia and roughened with age after splitting into columns. They formed sporulation rings and lacked exudates. Produced soluble pigments with a brown colour that was seen on the reverse of the colonies. Colonies were olive green on MEA with yellow green edges with velvet appearance.

They produced sclerotia and colourless exudates. Reverse colour was brown. On CYA the colonies were yellow at the centre surrounded by white mycelia. The colonies had deep yellow colour with sporulation rings and olive green edges. The conidia split into columns with age that gave the colonies a rough texture. Produced brown exudates and sclerotia but no soluble pigments. Reverse was dull yellow. Colonies on CZ were yellow and showed restricted growth; colourless exudates and brown sclerotia were produced. The amount of conidia on the plate were reduced leaving more of the thick white mycelia under the colonies. Reverse was dull brown as shown in Figure 2.

Predominantly they were uniserite with radiate conidia heads, of which some were knodding at the tip of the stipe. The vesicle were pyriform to globose and measured 24 - 29 (32) $\mu \mathrm{m}$ in diameter. Stipe length was (200) $320-480(1000) \times 8-12.8 \mu \mathrm{m}$ with thick and smooth walls which were uncoloured. Conidia size ranged between 4 - $5.8 \mu \mathrm{m}$; smooth; globose and green in colour. Diagnostic feature; Had nodding conidia heads at the tip of the stipe.

\section{3) Aspergillus parasiticus B (60612 BM 1 green)}

Colony diameters after 7 days of incubation at $25^{\circ} \mathrm{C}$; MEA 30 - $60 \mathrm{~mm}$ : CYA 30 - $65 \mathrm{~mm}$ : CZ 10 - $15 \mathrm{~mm}$; On PDA the colonies were yellow green with white to cream mycelia and yellow green edges. Sporulation rings formed in the colonies. The colonies produced exudates and soluble pigments with cream to pale yellow colour on the reverse; The colonies were olivaceous green with flucccose texture on MEA; They had white mycelia and formed furrows in the colonies; Produced brown sclerotia, exudates but no soluble pigments. The white parts had scattered conidia; Reverse was brown with radiating furrows. On CYA the colonies were yolk yellow to green conidia with white mycelia and velvet texture. They produced Small conidia heads, sclerotia and exudates, reverse colour was straw. Yellow colonies with white edges of young mycelia were formed on CZ with very slow growth and formed furrows. They produced exudates and brown sclerotia but no soluble pigments. Mycelia was cream to white and formed a mat beneath the colonies. The hyphal threads were very conspicous. Reverse was dark brown to cinnamon.

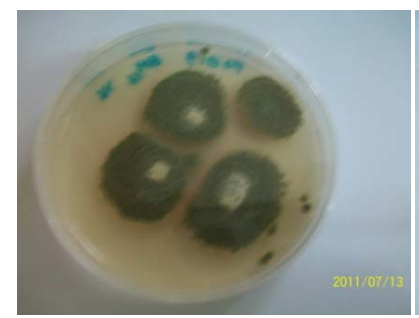

(a)

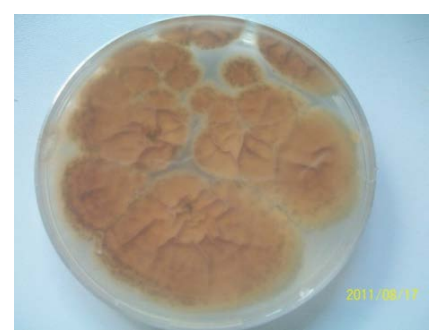

(e)

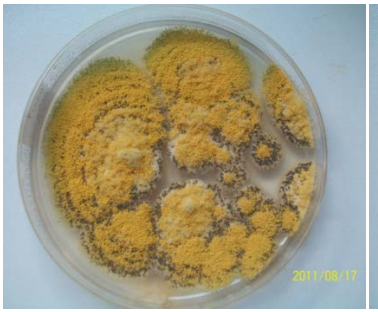

(b)

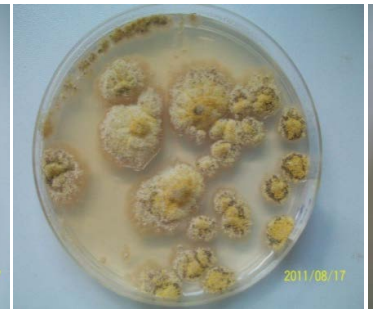

(c)

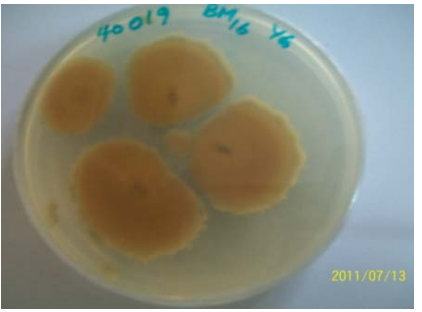

(d)

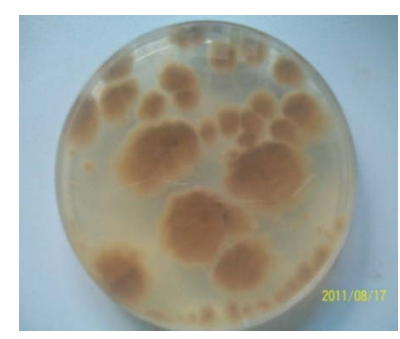

(f)

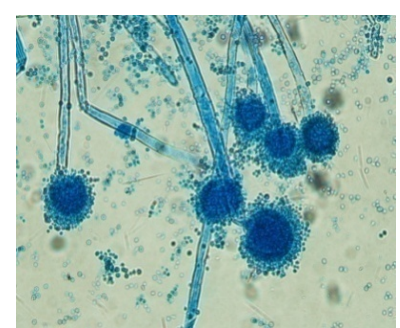

(g)

Figure 2. Aspergillus parasiticus A colonies on PDA (a \& d); CYA (b \& e); CZ (c \& f); (g) conidiophores and uniseriate conidia heads. 


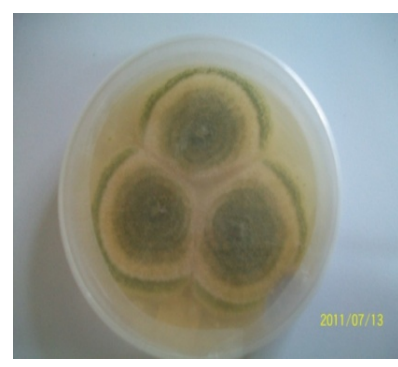

(a)

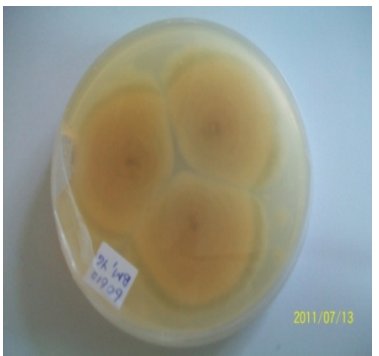

(d)

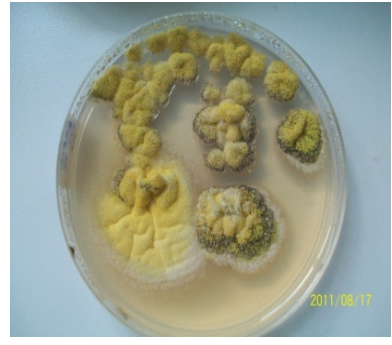

(g)

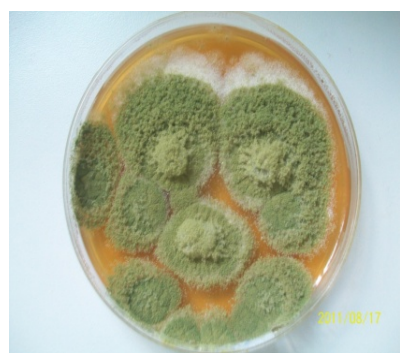

(b)

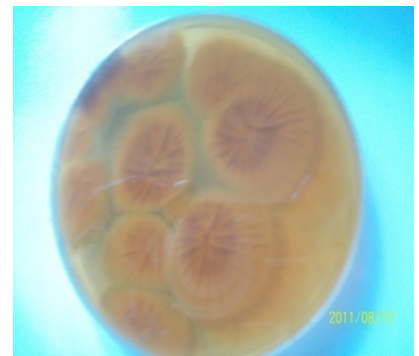

(e)

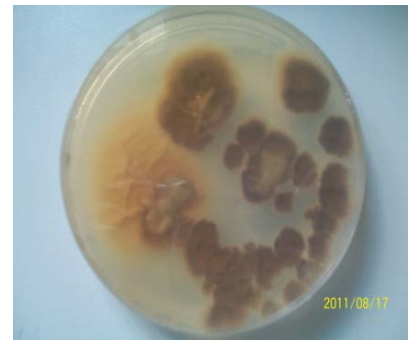

(h)

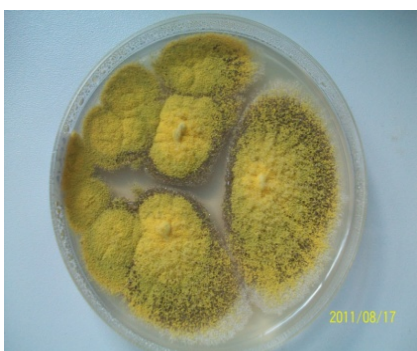

(c)

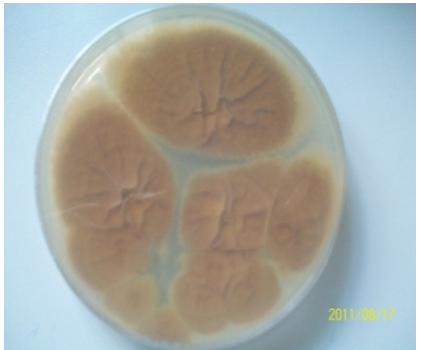

(f)

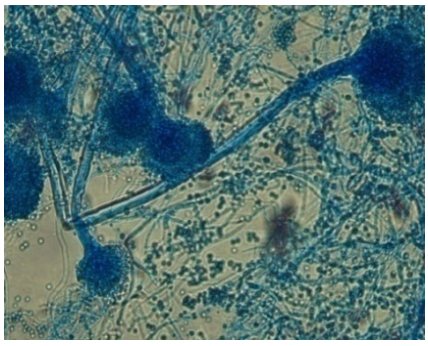

(i)

Figure 3. Aspergillus parasiticus B colonies on PDA (a \& d); MEA (b \& e); CYA (c \& f); CZ (g \& h); and (i) uniseriate conidia heads and stipe.

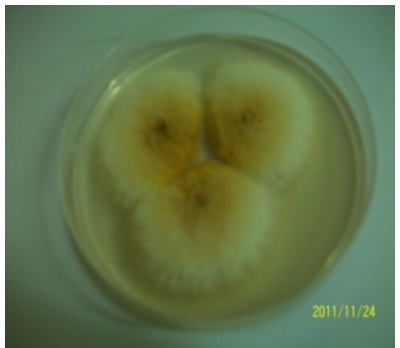

(a)

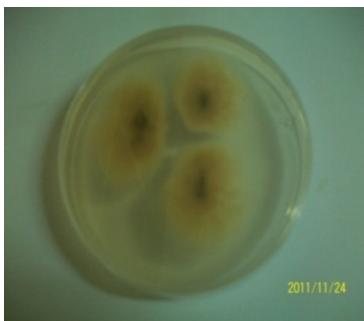

(e)

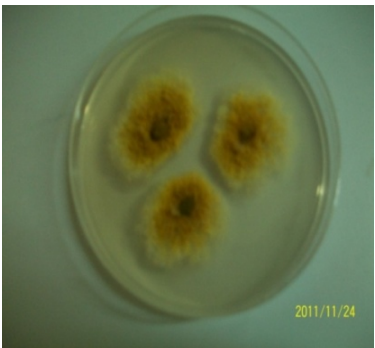

(b)

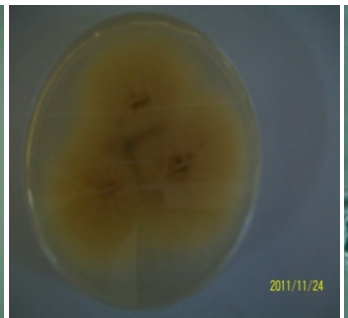

(f)

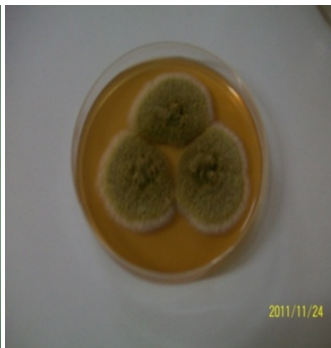

(c)

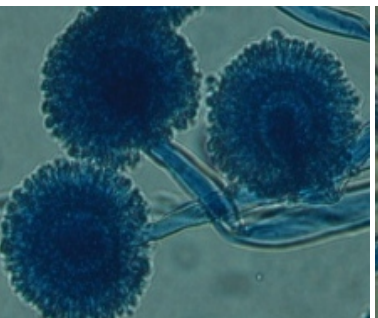

(g)

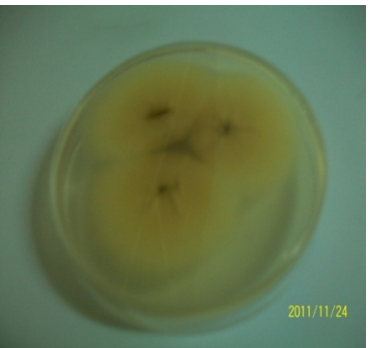

(d)

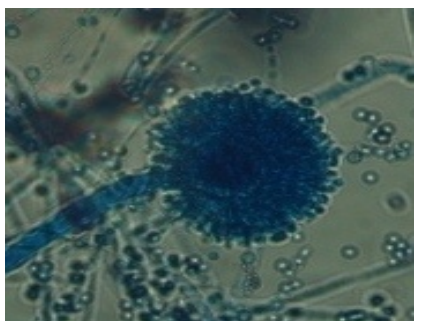

(h)

Figure 4. Aspergillus tamarii colonies on CYA (a \& d); CZ (b \& e); MEA (c \& f); biseriate conidia heads, vesicle and conidiophores (g \& h). 
They were uniseriate with at least $20 \%$ biseriate; Conidia heads were radiate with loosely attached phialides and pyriform to radiate vesicle that measured $19-35 \mu \mathrm{m}$ in diameter. Biseriates had globose vesicles and phialides covered three quarter of the vesicle: The conidiophores had rough walls, colourless and measured 200 - $440 \times 8$ - $16 \mu \mathrm{m}$ while the conidia size ranged between $3-7 \mu \mathrm{m}$; rough and yellow-green in colour. Diagnostic feature; Formed sporulation rings on PDA and produced a lot of sclerotia on CYA and CZ with restricted growth on CZ, Figure 3.

\section{4) Aspergillus tamarii (40243 BM 1 beige)}

Colony diameter after 7 days of incubation at $25^{\circ} \mathrm{C}$; PDA 32 - $35 \mathrm{~mm}$; MEA 45 - $55 \mathrm{~mm}$; CYA 50 - $65 \mathrm{~mm}$; CZ 50 - 55 mm: On PDA the colonies were cinnamon in colour with white mycelia and rough conidia. They produced exudates but no soluble pigments. Reverse was cream yellow with deep yellow colour at the edges. The colonies were olivaceous brown on MEA, they did not produce exudates nor soluble pigments. Due to uneven lengths of the conidiophores the colonies appeared rough. Reverse colour was brown. On CYA the colonies were cream yellow with thick fluccose white mycelia. They did not produce exudates nor soluble pigments; Reverse colour was pale brown. Colonies on CZ had deep yellow to orange colour at the centre with a fluccose texture and they produced colourless exudates as shown in Figure 4.

The conidia heads were biseriate and radiate measuring 64 - $69 \mu \mathrm{m}$ with globose vesicle measuring (20) 28 $43(50) \mu \mathrm{m}$ in diameter. The conidiophore stipe had rough and uncoloured walls measuring $640-900 \times 9$ - 18 $\mu \mathrm{m}$. Conidia size; 3 - $5 \mu \mathrm{m}$; globose; rough and green in colour. Diagnostic feature; Had very large conidia heads and rough conidia.

\subsubsection{Aspergillus Section Fumigati}

A total of 55 isolates belonging to this section were recovered from maize and soil samples. Three species of Aspergillus section Fumigati were identified A. duricaulis, A. fumigatus, A. novofumigatus A, and A. novofumigatus $B$, as shown in Figures 5-8.

\section{1) Aspergillus duricaulis (40034 BS 45 green)}

Colony diameter after 7 days of incubation at $25^{\circ} \mathrm{C}$; MEA 50 - $60 \mathrm{~mm}$; CYA; 50 - $55 \mathrm{~mm}$; CZ; 40 - $58 \mathrm{~mm}$; On PDA the colonies were dark green with colourless mycelia and lacked exudates and soluble pigments. Reverse colour was grey. Colonies on MEA were grey to pink, rough, with colourless mycelia and dark green edges; lacked exudates and soluble pigments. The reverse of the colony was dark brown. On CYA the colonies were pink with dirty brown edges, had colourless mycelia. Produced soluble pigments but showed no presence of exudates. The reverse of the colonies was deep pink to indigo. The colonies on CZ were cream yellow with colourless mycelia and dirty brown edges, lack exudates and produced pink soluble pigments in the media. Reverse colour was brown as shown in Figure 5.

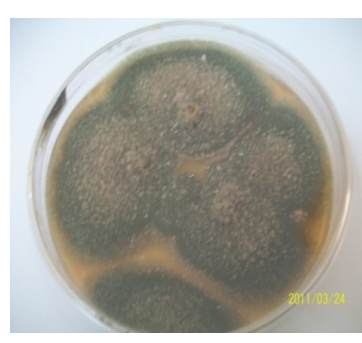

(a)

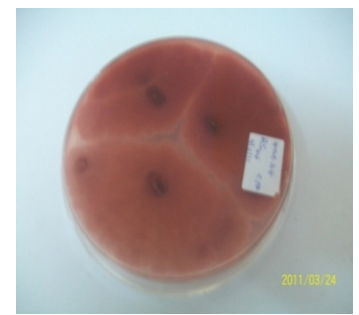

(e)

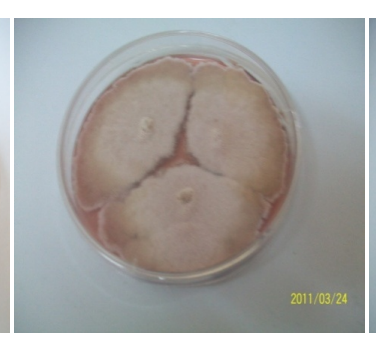

(b)

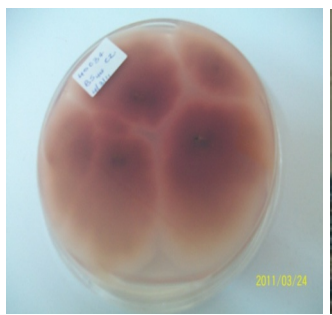

(f)

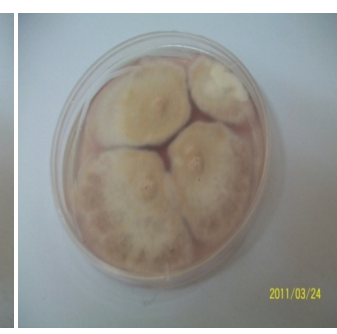

(c)

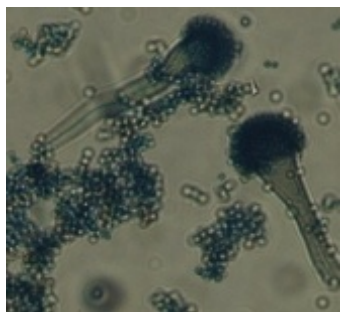

(g)

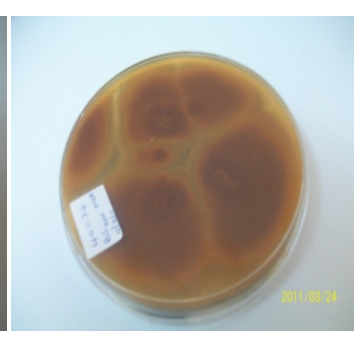

(d)

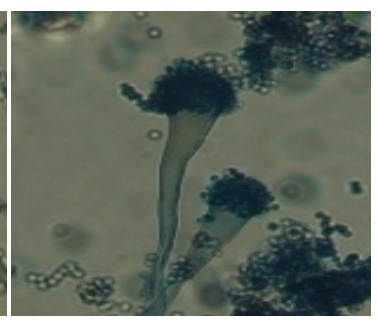

(h)

Figure 5. Aspergillus duricaulis colonies on MEA (a \& d); CYA (b \& e); CZ (c \& f); (g) conidia (h) semi clavate conidiophores. 
Exclusively they were uniseriate with short columnar conidia head. Majority had pyriform vesicle while others were sub-clavate measuring $10-26 \mu \mathrm{m}$ in diameter. Conidiophores were short and measured between 50 $350 \times 3.5-10 \mu \mathrm{m}$, with thick and smooth walls. The conidia were small in size; 2 - $3.5 \mu$ m, globose to ellipsoidal in shape with a smooth and finely rough texture. Distinguishing feature; had thick walled stipe (6 - 10 $\mu \mathrm{m})$, large pyriform to semi clavate vesicle, Figure 5 .

\section{2) Aspergillus fumigatus (40034 BS 46 green)}

Colony diameter after incubation at $25^{\circ} \mathrm{C}$ for 7 days; PDA 40 - 50 mm; MEA 24 - 40 mm; CYA 20 - 30 mm; CZ 18 - 25 mm; On PDA the colonies were greenish grey with conidia which were rod shaped and colourless mycelia; There was no presence of exudates and soluble pigments; reverse was greyish ash or olivaceous grey. On MEA the colonies were deep green with white mycelia; lacked exudates and soluble pigments; reverse colour was cinnamon. The colonies were pink to white on CYA with slow growth of the colonies as compared to growth on MEA. Reverse was straw. On CZ the colonies were similar in macro morphological characteristics as on CYA the mycelia were colourless with no exudates and soluble pigments as shown in Figure 6.

They had short columnar and uniseriate conidia heads; vesicle diameter and shape; 19 - $31 \mu \mathrm{m}$, spaulate to clavate; majority had the phialides covering half to three quarter of the vesicle; The conidiophore stipe measured 280 - $440 \times 4.8$ - $8.0 \mu \mathrm{m}$ smooth and straw in colour; it expanded towards the tip or the vesicle. Conidia size; 2 $3 \mu \mathrm{m}$, globose finely rough and plain green. Diagnostic features; The stipe expanded towards the tip forming flask shaped as it joined the vesicle; have very short conidia heads and conidiophores and small conidia.

\section{3) Aspergillus novofumigatus A (40026 BS 39 green)}

Colony diameters after 7 days at $25^{\circ} \mathrm{C}$; MEA 25 - 30 mm; CYA 50 - 60 mm; CZ 18 - 20 mm. The colonies on PDA were leafy green with diurnal sporulation with white mycelia; reverse was greyish green. On MEA colonies were olive with white mycelia between and under the colonies while some formed mats of mycelia on the media. They produced colourless exudates but lacked soluble pigments; had rod shaped conidia that split into columns with age. Reverse colour was brown. The colonies on CYA were deep yellow with olivaceous green edges and formed furrows; they had velvet texture and produced colourless exudates but no soluble pigments with straw colour on the reverse straw. On CZ the colonies showed restricted growth with yellow colouration and formed heaps with white mycelia under the colonies. Isolates produced colourless exudates and no soluble pigment. The texture of the colonies was rough and others had a conspicuous hyphal threads arising from the colony (Figure 7).

They had long columnar conidia heads, uniseriate with loosely attached phialides. The vesicle was pyriform to radiate measuring $21-29 \mu \mathrm{m}$ in diameter and the stipe measured $290-483(1000) \times 8$ - $10 \mu$ m; conidia size was 4 - $7 \mu \mathrm{m}$, smooth, globose and green. Diagnostic feature: They had varied shapes of the stipe and neck,

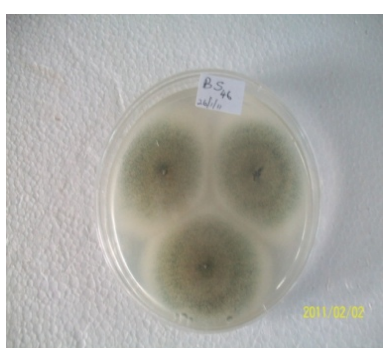

(a)

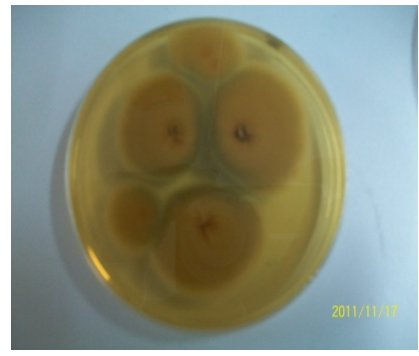

(e)

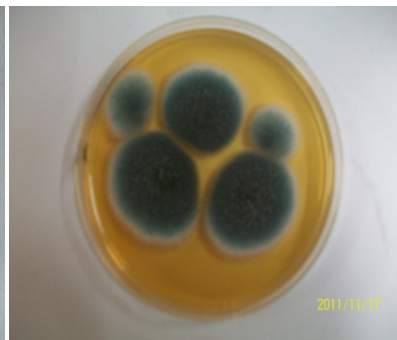

(b)

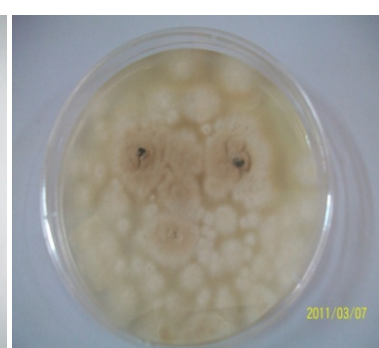

(c)

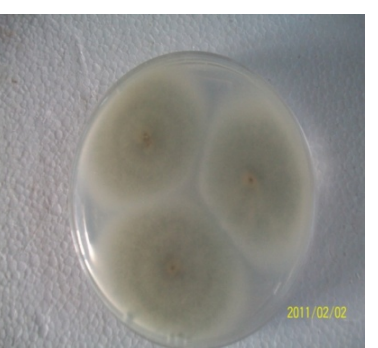

(d)

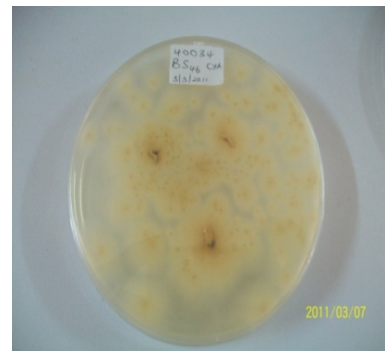

(f)

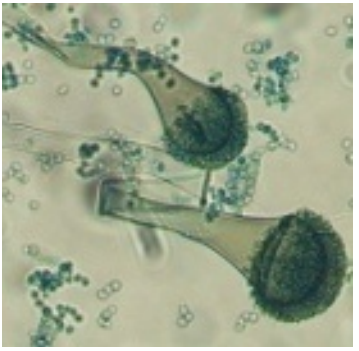

(g)

Figure 6. Aspergillus fumigates colonies on PDA (a \& d); MEA (b \& e); CYA (c \& f); (d) stipe and short conidia head. 
some expanded towards the vesicle while others had same width of the stipe expanding up to the vesicle. The phialides covered three quarter of the vesicles.

\section{4) Aspergillus novofumigatus $B$ (40034 BS 42 green)}

Colony colours after incubation for 7 days at $25^{\circ} \mathrm{C}$; PDA 40 - $45 \mathrm{~mm}$; MEA 40 - $50 \mathrm{~mm}$; CYA 35 - $40 \mathrm{~mm}$. On PDA the colonies were dark green with white mycelia at the edges although white thick mycelia formed under the colonies. The colonies had a rough texture and they lacked exudates and soluble pigments; reverse was green yellow; On MEA the colonies were deep green with rod shaped conidia; colonies appeared smooth when young but roughened with age. They produced a lot of conidia. There was no presence of exudates and soluble pigments. Reverse colour was dark brown. On CYA the colonies had a white to pink appearance with white mycelia and finely rough texture. The exudates produced were colourless. Reverse colour was straw to cream.

Conidia heads were long columnar, uniseriate with some having phialides compactly packed on the vesicle while others had phialides loosely packed (Figure 8). The vesicle were pyriform to radiate measuring between $11-21 \mu \mathrm{m}$ in diameter with phialides covering three quarters of the vesicle and in some only half the vesicle was covered. Stipe measured $240-440(600) \times 4.8-12.9 \mu \mathrm{m}$ and it was smooth and light brown. They produced a lot of conidia ranged between $3-5 \mu \mathrm{m}$, globose, rough and green in colour. Diagnostic feature: The colonies were dark green both on PDA and MEA and compactly packed conidia heads.

\subsubsection{Aspergillus Section Nigri}

Aspergillus section Nigri was second highest next to section Flavi across the locations with a total frequency of (64/51) from maize and soil. Six species were identified and these were A. heteromorphus, A. carbonarious, A. aculeatus $A$, A. aculeatus $B$, A. niger, A. japonicus, A. brasiliesis, as shown in Figures 9-15.

\section{1) Aspergillus heteromorphus (40063 BM 1 black)}

Colony diameters after 7 days of incubation at $25^{\circ} \mathrm{C}$; MEA 35 - $45 \mathrm{~mm}$, CYA 50 - $55 \mathrm{~mm}$; CZ 45 - $50 \mathrm{~mm}$; On PDA the conidia were very black with colourless mycelia; Produced a lot of conidia but lacked exudates and soluble pigments. Reverse color was straw. The conidia were very black on MEA with inconspicuous white mycelia at the edge of the colonies, Figure 9. The colonies had floccose texture with no presence of exudates and soluble pigments. Radial furrows were formed in the colony. Reverse was cinnamon with distinct radial furrows. On CYA there were scattered black conidia onto the thick cream mycelia that gave the colony light white to cream colonies with white mycelia at the edges. The colonies grew faster as compared to growth on MEA. They formed radial furrows in the colony and produced colourless exudates but no soluble pigments. Reverse was

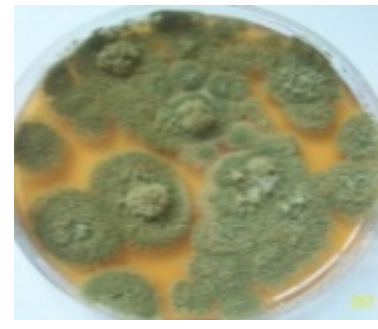

(a)

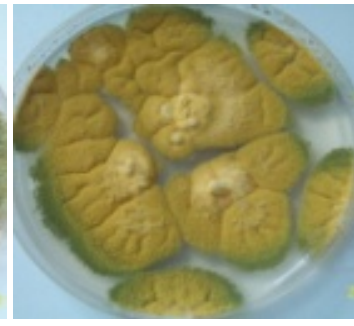

(b)

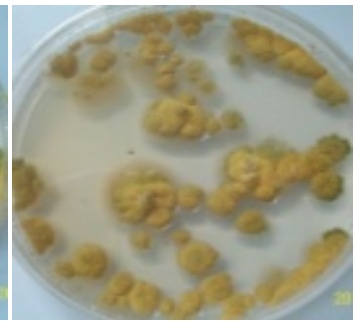

(c)

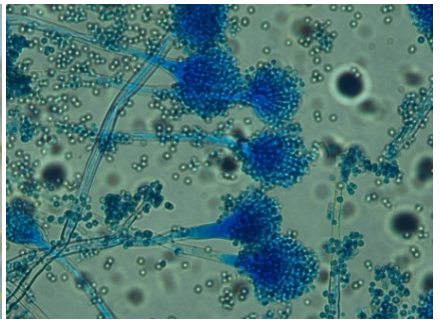

(d)

Figure 7. Aspergillus novofumigatus A Colonies on MEA (a); CYA (b); CZ (c); (d) columnar conidia head and expanding conidiophores.

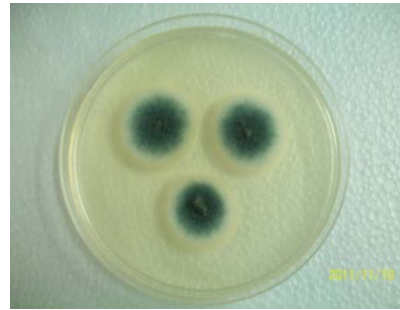

(a)

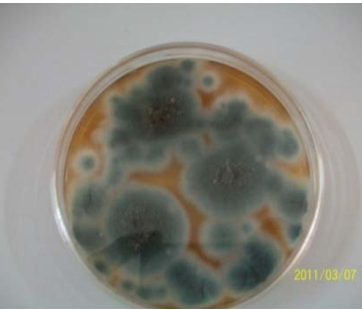

(b)

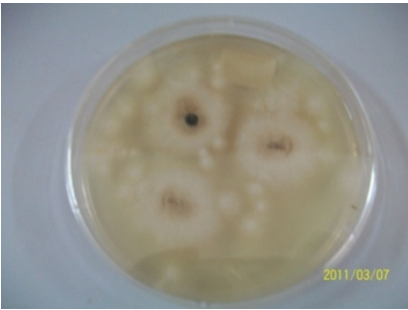

(c)

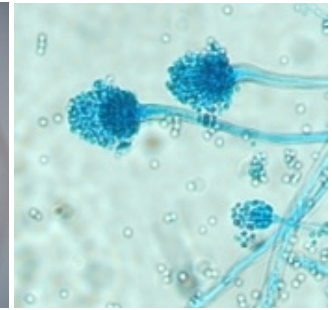

(d)

Figure 8. Aspergillus novofumigatus colonies on PDA (a); MEA (b); CZ (c); (d) columnar conidia head and conidiophores. 


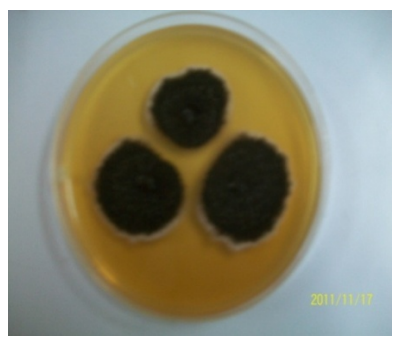

(a)

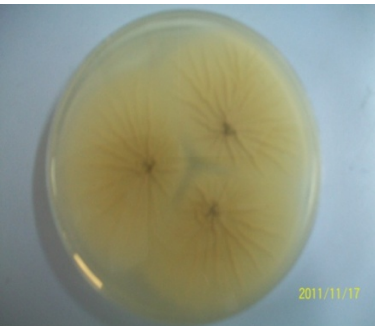

(e)

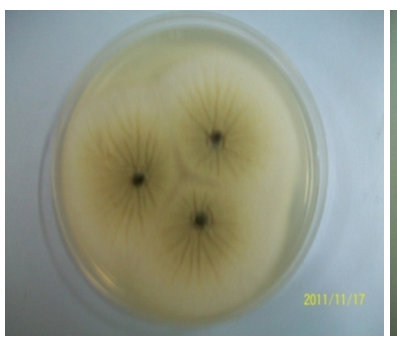

(b)

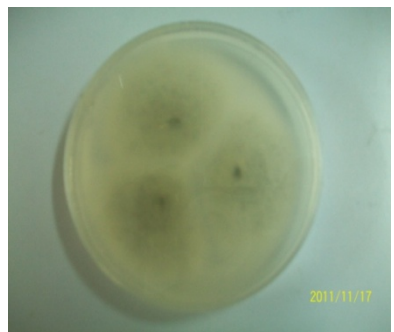

(f)

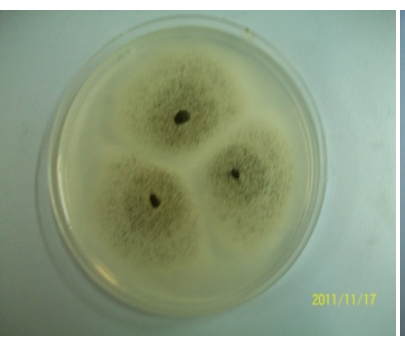

(c)

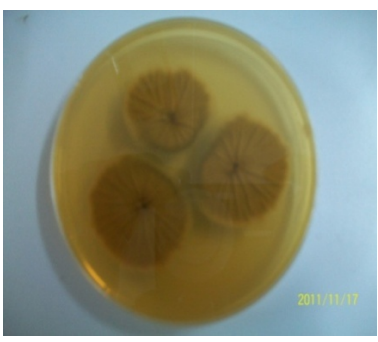

(d)

Figure 9. Aspergillus heteromorphus colonies on MEA (a \& d); CYA (b \& e); CZ (c \& f); (g) biseriate, conidia head and vesicle.

straw to cream with distinct furrows. The colonies on CZ had black conidia scattered onto the thick white mycelia, produced colourless exudates but no soluble pigments. Reverse color was grayish green.

They were predominantly biseriate with sub globose and globose conidia heads with compact phialides. The vesicle was globose and others sub globose with a diameter of $12-16 \mu \mathrm{m}$. Conidiophores measured $360-400 \times$ 4 - $8 \mu \mathrm{m}$. The conidia sizes ranged between 3.5 - $4 \mu \mathrm{m}$, rough, globose and brown in colour; diagnostic feature; had very small vesicle $12-16 \mu \mathrm{m}$.

\section{2) Aspergillus carbonarius (40041 BS 113 black)}

Colony diameter after incubation at $25^{\circ} \mathrm{C}$ for 7 days; MEA 40 - $60 \mathrm{~mm}$; CYA 60 - $63 \mathrm{~mm}$; CZ 26 - $30 \mathrm{~mm}$; On MEA, the colonies were date brown with velvet appearance. They had cream to white thick floccose mycelia underneath the colonies and at the edges of the colonies. The conidia were rough and split into columns with age. They formed furrows within the colonies lacked exudates and soluble pigments. There was slow growth of the colonies as compared to growth on CYA. Reverse was beige. Colonies on CYA were light brown and formed furrows with few brown conidia scattered onto the mycelia. Exudates were present but no soluble pigments. Reverse colour was yellow to straw. The colonies on CZ were light to date brown with long hyphal threads onto which big globose conidia were attached. They had thick cream mycelia and produced exudates. Colony reverse was straw.

Predominantly they were biseriate with subglobose to globose conidia head (Figure 10). The vesicles were globose others formed umbrella shapes measuring $41-60 \mu \mathrm{m}$ in diameter. Stipe; measured $640-800(1000) \times$ (13) 16 - $20 \mu \mathrm{m}$ with thick and smooth walls brown in colour. The phialides covered three quarters of the vesicle. Conidia size ranged between (6) 7 - 10 (11) $\mu \mathrm{m}$, globose, with rough walls and black. Diagnostic feature; had very large vesicle and black conidia.

\section{3) Aspergillus aculeatus A (40091 BM 82 black)}

Colony diameters after 7 days of incubation at $25^{\circ} \mathrm{C}$ : PDA 35 - $45 \mathrm{~mm}$; MEA 37 - $49 \mathrm{~mm}$; CYA 40 - $50 \mathrm{~mm}$; CZ 40 - $53 \mathrm{~mm}$; The colonies on PDA were black to dark brown and conidia split into columns with age that gave colonies a rough texture. Formed radial furrows with inconspicuous white mycelia underneath the colonies. No exudates but produced lemon yellow soluble pigments. Reverse was yellow with distinct radial furrows. On MEA the colonies were very black with floccose texture. They had white mycelia that grew inconspicuously on the colonies giving it a greyish appearance. Beneath the colonies they formed a thick a mat of mycelia which were visible at the edges. There were no soluble pigments and exudates. Reverse was berge or cinnamon. The colonies on CYA were yellow colour, deep yellow and rough mycelia with very little black scattered conidia that gave black centre where there was high concentration of the conidia. They lacked exudates and soluble pigments with yellow reverse colour. On CZ the colony morphologies were similar to those of CYA although the mycelia 


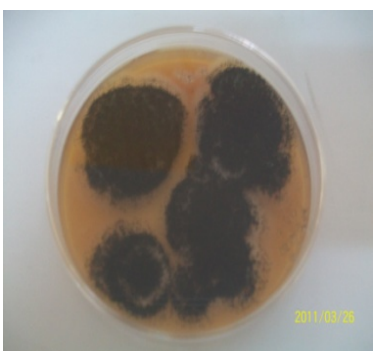

(a)

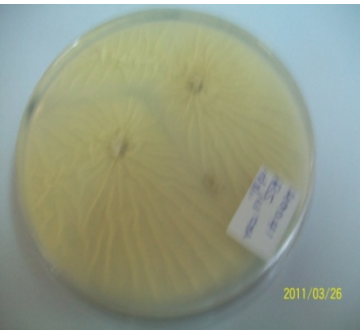

(e)

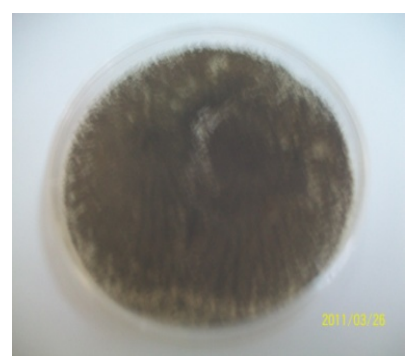

(b)

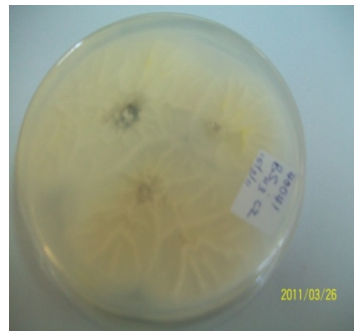

(f)

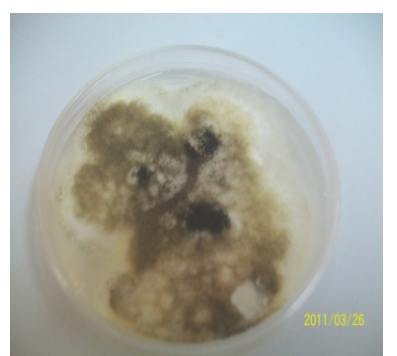

(c)

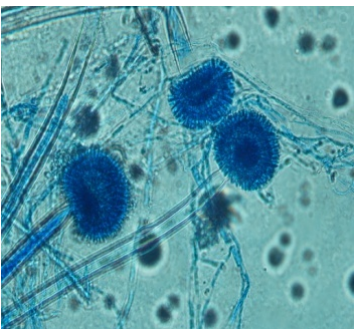

(g)

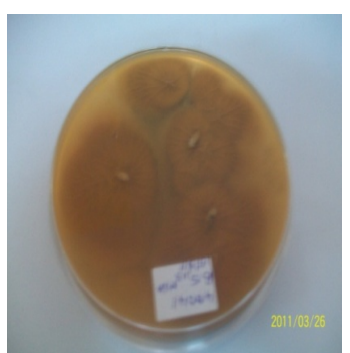

(d)

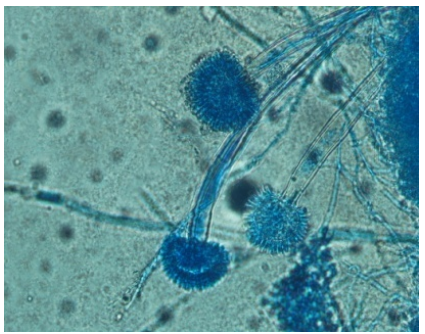

(h)

Figure 10. Aspergillus heteromorphus colonies on MEA (a \& d); CYA (b \& e); CZ (c \& f); (g) biseriate, conidia head and vesicle.

colour was light yellow and formed radial furrows. Reverse was deep yellow with distinct furrows as shown in Figure 11.

Predominantly they were uniseriate with globose conidia heads and spherical to globose vesicle with a diameter ranging from 48 - $74 \mu \mathrm{m}$. The conidiophores were short and measured $210-321 \times 10-18 \mu \mathrm{m}$, thick and smooth walls which were uncoloured. Conidia were globose with rough walls and varied in sizes between $4-5$ $\mu \mathrm{m}$ and brown in colour. Diagnostic feature; had ver short conidiophores and wide vesicles.

\section{4) Aspergillus aculeatus B (40332 BM 1 brown)}

Colony diameters after 7 days of incubation at $25^{\circ} \mathrm{C}$; MEA 50 - 60 mm: CYA 60 - 65 mm; CZ 50 - 60 mm; On PDA, the colonies were cocoa brown, small conidia were produced that split with age. They had colourless mycelia with presence of exudates. Reverse was olivaceous buff. The colonies on MEA were date brown with colourless mycelia; the conidia were large with a rough texture. They lacked exudates and soluble pigments, with brown reverse. On CYA the colonies had coffee brown colour with rough texture, and colony growth was fast as compared to growth on MEA. Mycelia were cream, formed radial furrows and did not produce exudates and soluble pigments. Reverse was brown to dark brown. The colonies were cocoa brown on CZ with lots of conidia and thick white mycelia growth beneath the colonies. There were no exudates and soluble pigments and cream to dirty grey colour on the reverse (Figure 12).

They were uniseriate with very large and globose conidia head; the vesicle measured 45 - $73 \mu \mathrm{m}$ in diameter and globose in shape. Stipe had thick walls that measured $260-550 \times 10-12 \mu \mathrm{m}$ and brown in colour. Conidia sizes ranged between 4 - $5 \mu \mathrm{m}$; rough; globose and brown. Diagnostic feature, had very wide vesicle and short conidiophores.

\section{5) Aspergillus niger (40060 BM 1 black)}

Colony diameters after 7 days of incubation at $25^{\circ} \mathrm{C}$; PDA 40 - 50 mm; MEA 45 - 55 mm; CYA 50 - 60 mm; CZ 50 - 65 mm; On MEA colonies were date brown with white to cream thick mat of floccose mycelia beneath the colonies and at the edges. It formed radial furrows very close to each other. They lacked soluble pigments and exudates. Reverse was brown; Colonies on CYA were white to olivaceous in colour with a thick mat of white mycelia beneath the colonies formed radiating furrows on the colony. There was fast growth of the colonies, produced exudates but no soluble pigments. Reverse was pale brown to yellow. On CZ the colonies were olivaceous buff changed colour to brown with age. They produced black conidia at the centre and white mycelia towards the edge. Exudates were present. Reverse was greyish to straw.

Conidia heads were biseriate and globose in shape with wide spherical to globose vesicle that measured 37 - 52 $\mu \mathrm{m}$ (Figure 13). The stipe measured 440 - $680 \times 6-12 \mu \mathrm{m}$ with smooth and slightly brown in colour; Conidia 


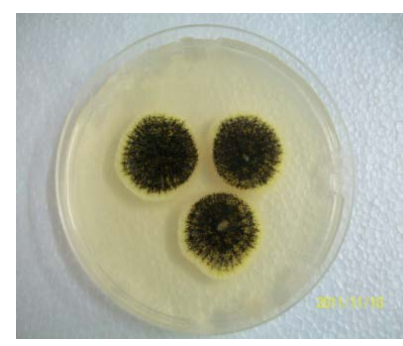

(a)

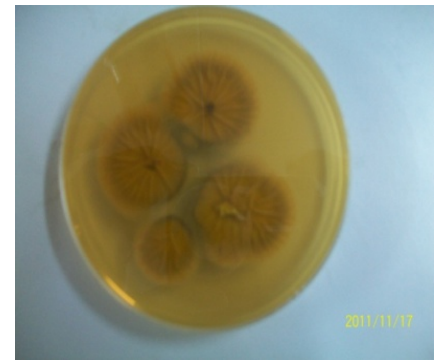

(e)

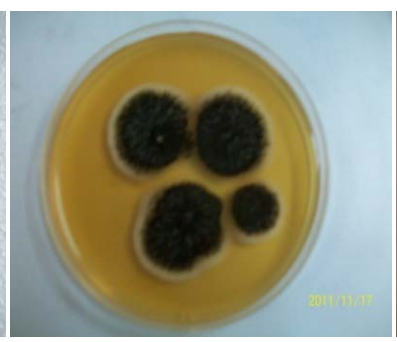

(b)

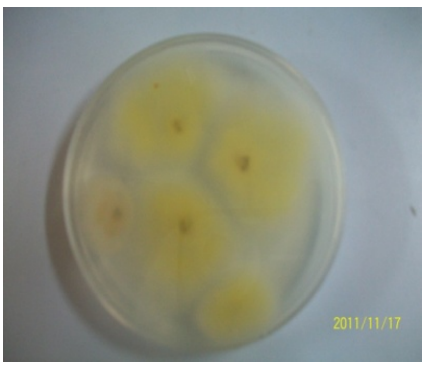

(f)

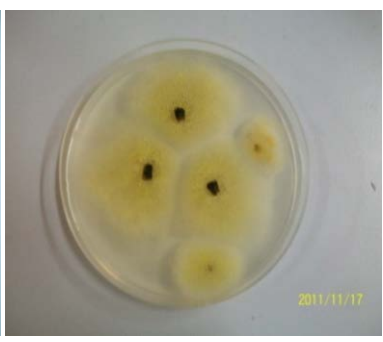

(c)

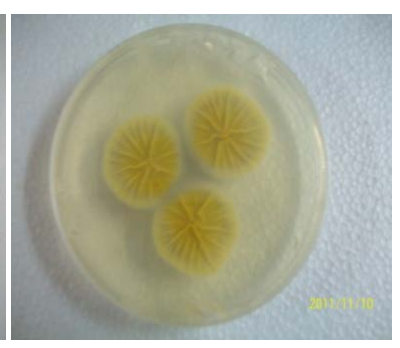

(d)

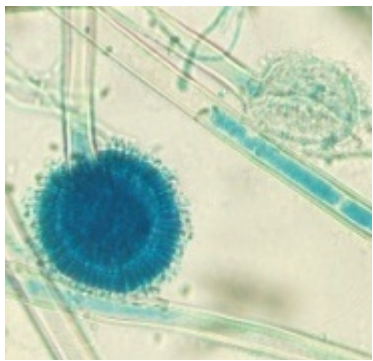

(g)

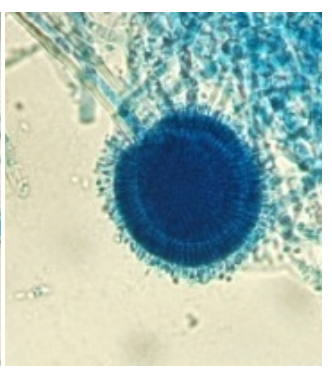

(h)

Figure 11. Aspergillus aculeatus A colonies on PDA (a \& d); MEA (b \& e); CYA (c \& f); (g \& h) uniseriate conidia head and pyriform vesicle.

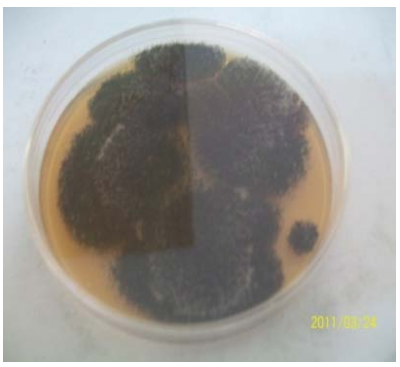

(a)

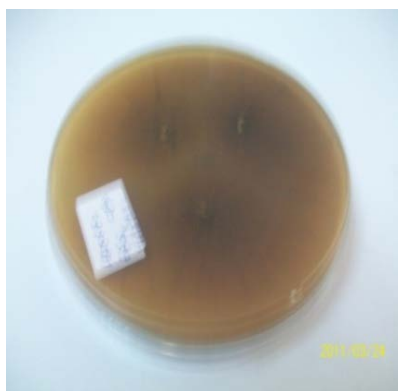

(e)

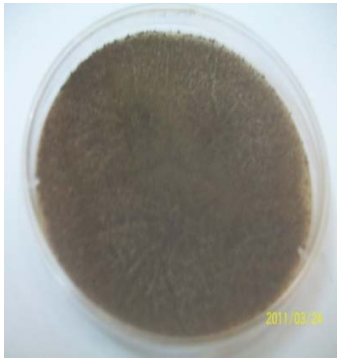

(b)

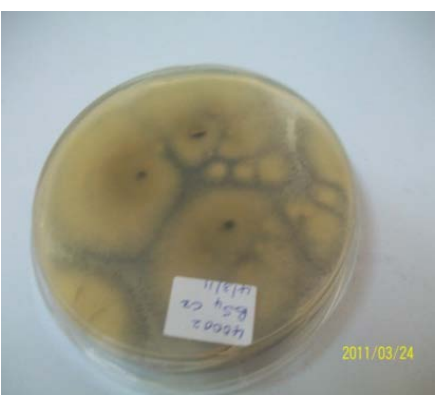

(f)

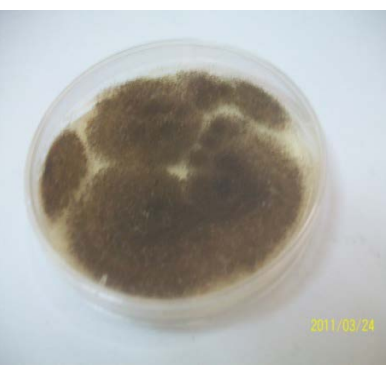

(c)

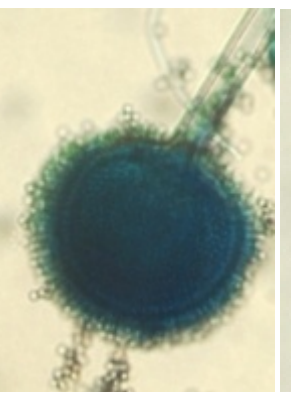

(g)

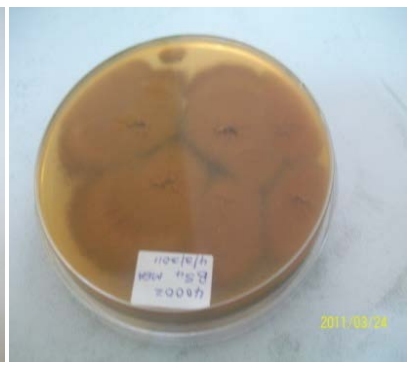

(d)

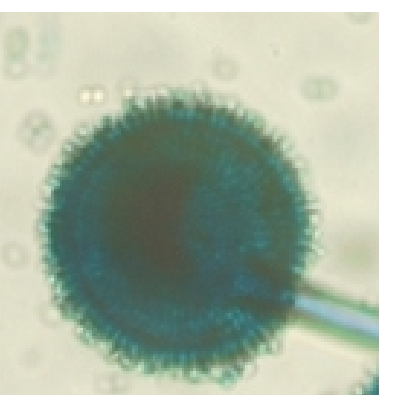

(h)

Figure 12. Aspergillus aculeatus B colonies on MEA (a \& d); CYA (b \& e); CZ (c \& f); (g \& h) uniseriate conidia head large vesicle.

varied in sizes ranging from 4 - 6 um, rough texture, globose and brown. Diagnostic feature; they had large and wide stipe.

6) Aspergillus japonicus (40004 BS 57 brown)

Colony diameters after 7 days of incubation at 25두 MEA 45 - 50 mm; CYA 55 - 65 mm; CZ 45 - 55 mm. The colonies on MEA were coffee brown with inconspicuous white mycelia under the colonies. The colony texture was floccose, lacked exudates and soluble pigments. Reverse colour was cinnamon to brown. On CYA the colonies had cocoa brown appearance to brown with no exudates and soluble pigments. White mycelia formed a 


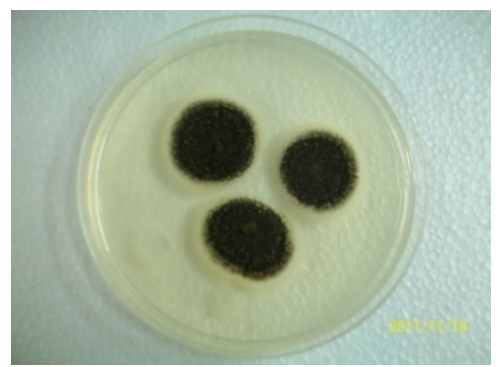

(a)

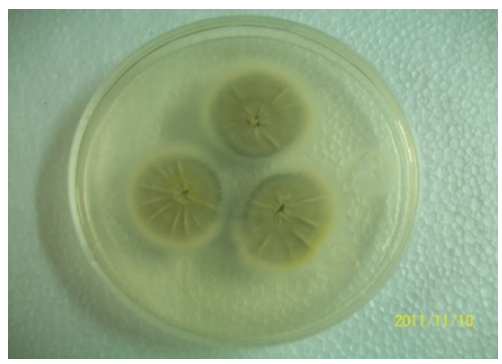

(d)

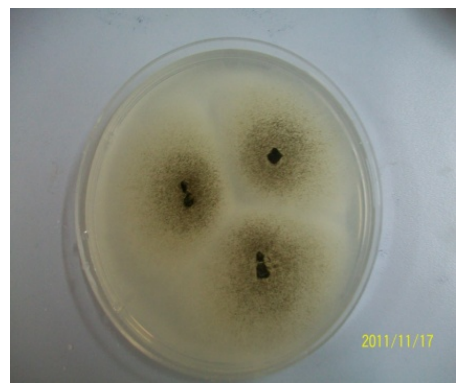

(g)

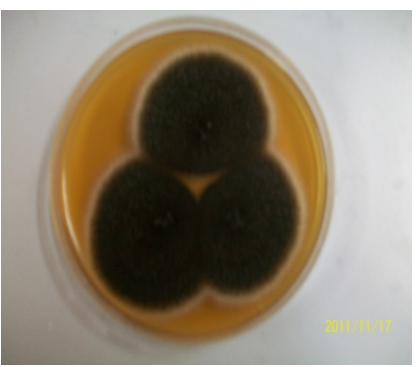

(b)

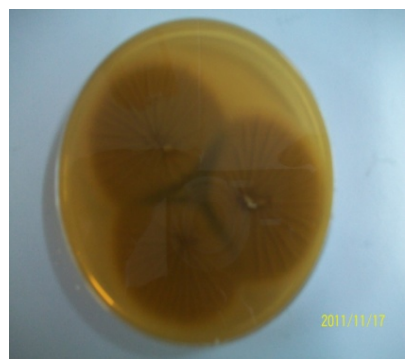

(e)

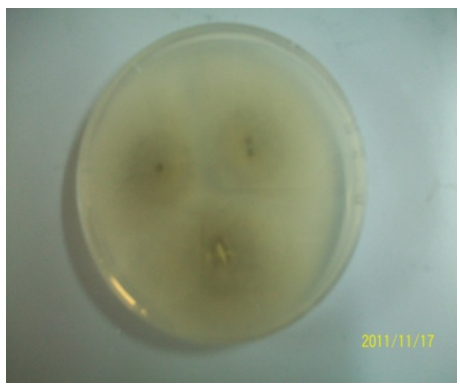

(h)

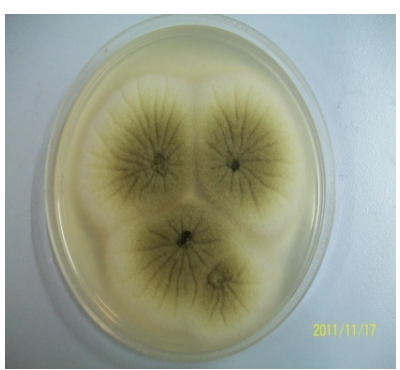

(c)

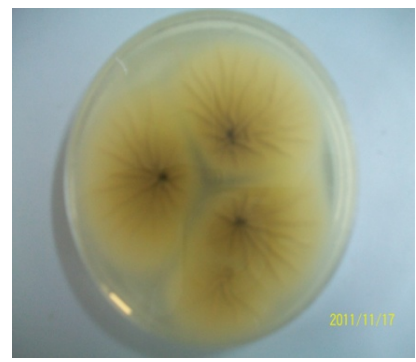

(f)

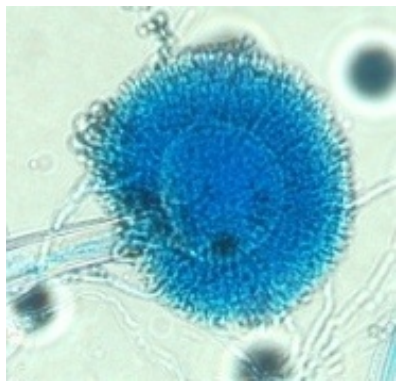

(i)

Figure 13. Aspergillus niger colonies on PDA (a \& d); MEA (b \& e); CYA (c \& f); CZ (g \& h); (j) Biseriate, globose conidia heads and vesicle.

mat beneath the colonies. Reverse was dirty brown; colonies on CZ were black with scattered conidia on thick and rough white mycelia. They lacked exudates and soluble pigments and had straw to cream colour on the reverse.

Exclusively they were uniseriate with radiate conidia head and globose to ellipsoidal vesicle measuring 29 $45 \mu \mathrm{m}$ in diameter. The stipe had thick and smooth walls, brown in colour that measured 258 - $620 \mu \mathrm{m}$. Conidia sizes ranged between 3 - $5 \mu \mathrm{m}$, globose, smooth and brown. Diagnostic feature; had very short conidiophores as shown in Figure 14.

\section{7) Aspergillus brasiliensis (40021 BS 17 black)}

Colony diameters after incubation for 7 days at 25두 PDA 40 - 50 mm; MEA 45 - 50 mm; CYA 50 - 60 mm. Colonies were very black on PDA forming sporulation rings with white and rough mycelia and produced very large and round conida that split into columns with age. Exudates and soluble pigments were absent. Reverse had alternating rings of grey, yellow and orange to cream at the centre. On MEA the conidiation area was black with white mycelia around it. They lacked exudates and soluble pigments; reverse colour was brown. The colonies on CYA were white to pink with white and rough mycelia. There was presence of colourless exudates but no soluble pigments with straw colour on reverse.

They were exclusively biseriate with globose conidia heads and closely packed phialides covering the entire vesicle. Some vesicles were globose while others pyriform in shape with a diameter that measured 32 - $38 \mu \mathrm{m}$ as shown in Figure 15. The stipe measured 650 - $1100 \times 9-12 \mu \mathrm{m}$, had thick and smooth walls, brown in colour. Conidia sizes ranged 3 - $4.5 \mu \mathrm{m}$; rough and brown. Diagnostic feature; the colony had distinct sporulation rings on PDA and long stipe. 


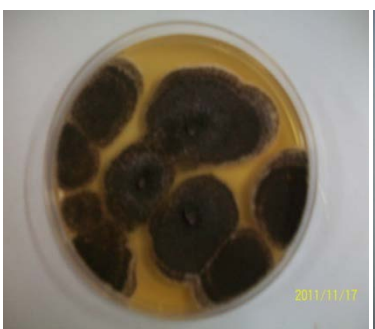

(a)

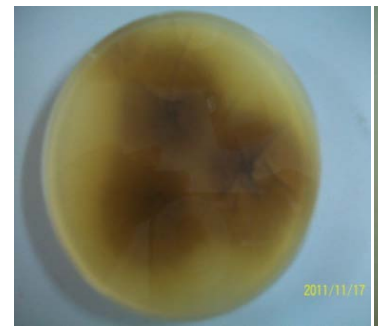

(e)

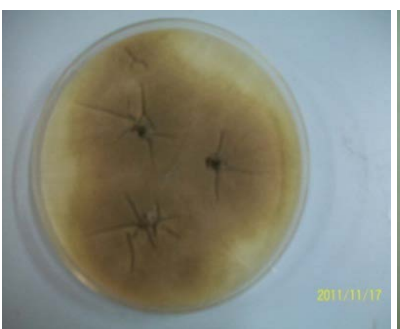

(b)

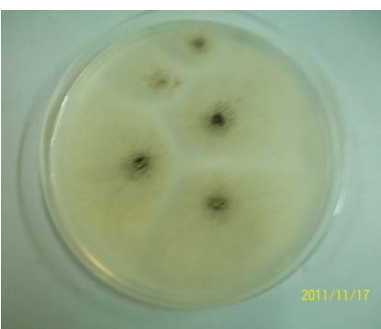

(c)

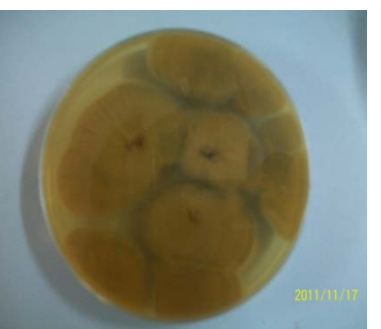

(d)

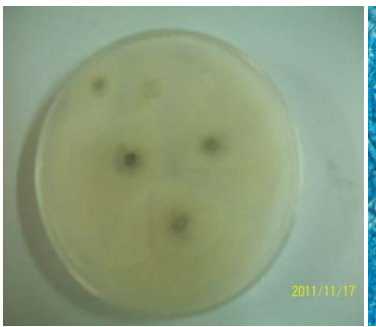

(f)

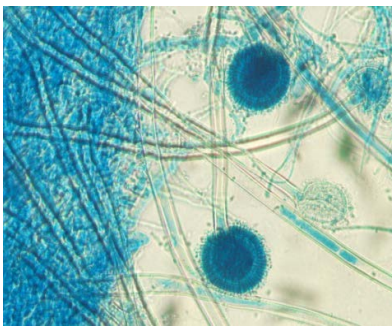

(g)

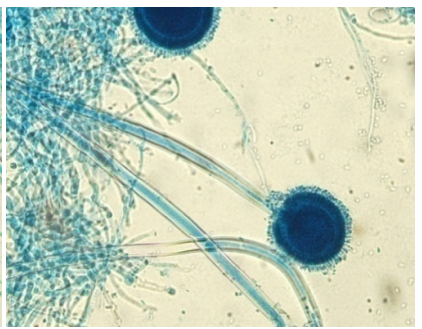

(h)

Figure 14. Aspergillus japonicus colonies on MEA (a \& d); CYA (b \& e); CZ (c \& f); (g \& h); Conidiophores, uniseriate conidia head, and pyrifom vesicle.

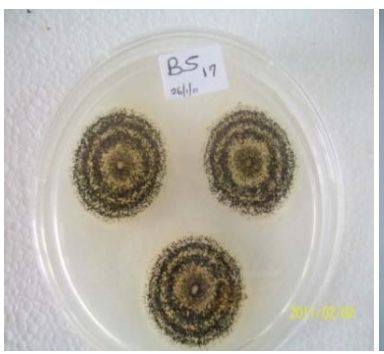

(a)

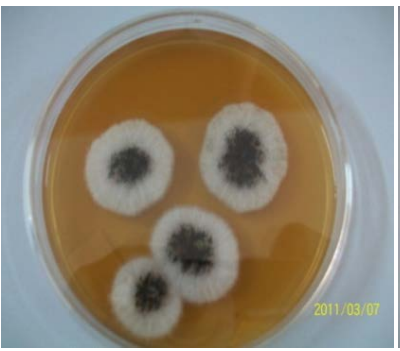

(b)

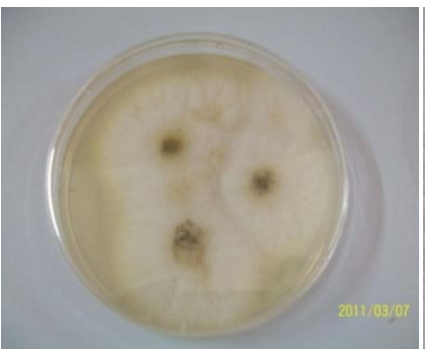

(c)

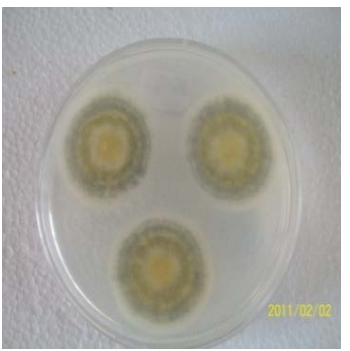

(d)

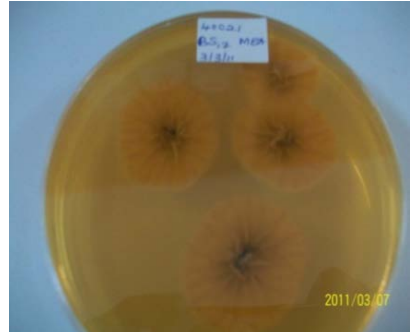

(e)

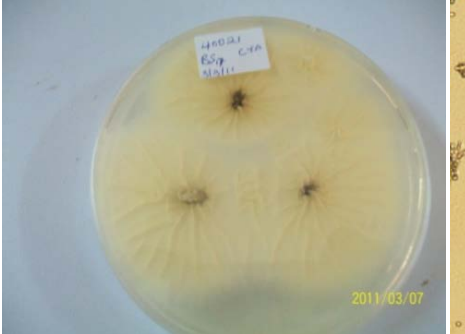

(f)

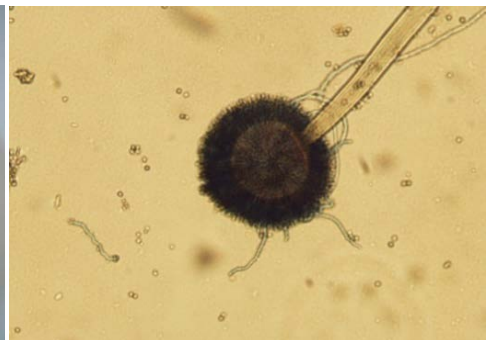

(g)

Figure 15. Aspergillus brasiliensis colonies on PDA (a \& d); MEA (b \& e); CYA (c \& f); (d) biseriate, globose conidia head and vesicle.

\subsubsection{Aspergillus Section Circumdati}

Nine isolates of Aspergillus section Circumdati were recovered, eight from maize and one from the maize soils. The species identified were A. ochraceous and A. ostianus shown in Figure 16 and Figure 17.

\section{1) Aspergillus ochraceus (40089 BM 79 orange)}

Colony diameter after 7 days of incubation at 25두 PDA 40 - 50 mm; MEA 25 - 30 mm; CYA 40 - 50 mm; CZ 20 - 25 mm. Colonies were orange or cinnamon on PDA with colourless mycelia, lacked exudates and soluble pigments. Reverse colour was yellow; On MEA the colonies were cream with white mycelia that formed a mat on the media and at the edges. They had smooth texture and produced brown exudates. More conidia were compared to what was formed on CYA. Reverse colour was dirty brown with cream edges (Figure 16). The colonies on CYA were white to cream with ochraceus centre; had smooth to rough texture and produced little 


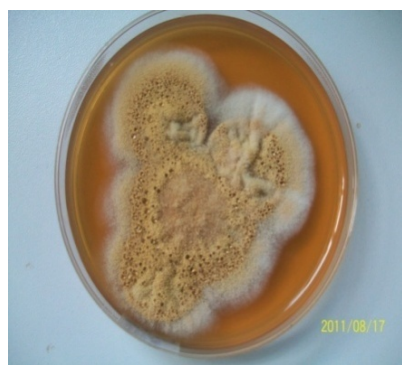

(a)

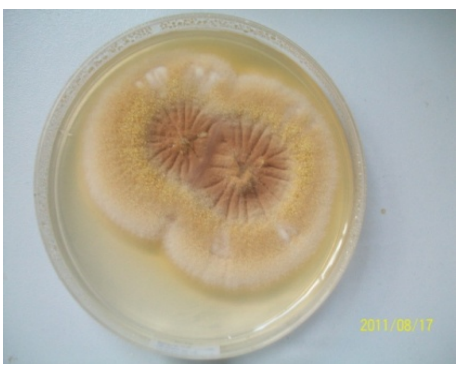

(b)

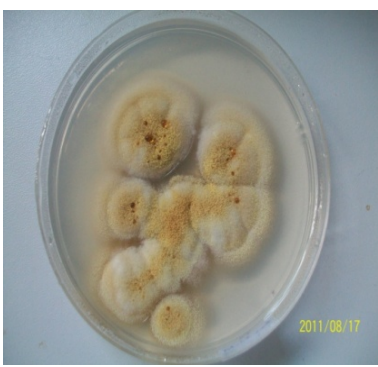

(c)

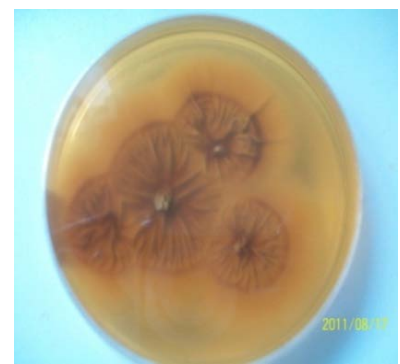

(d)

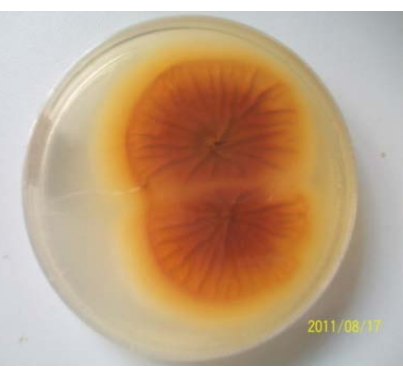

(e)

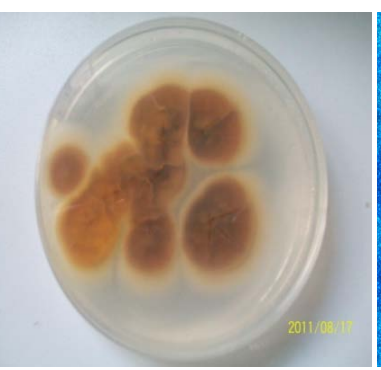

(f)

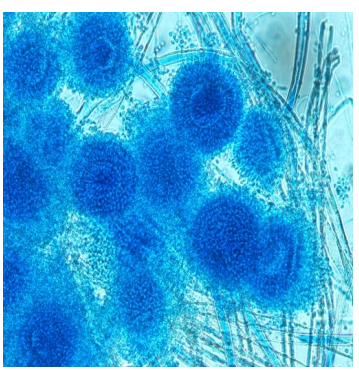

(g)

Figure 16. Aspergillus ochraceus colonies on MEA (a \& d); CYA (b \& e); CZ (c \& f); (g) distinct globose conidia head.

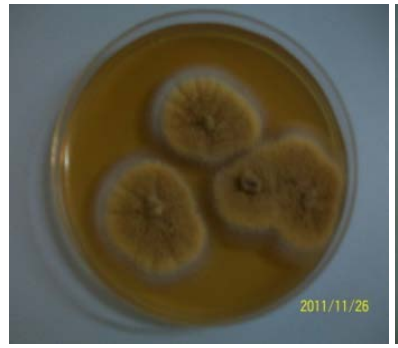

(a)

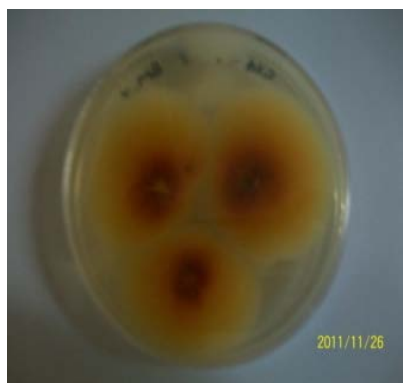

(e)

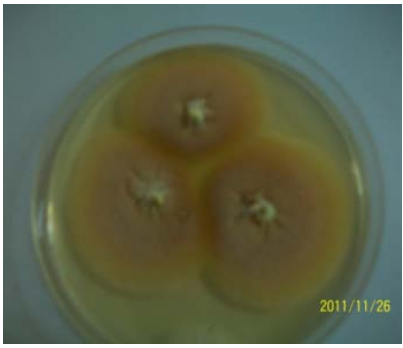

(b)

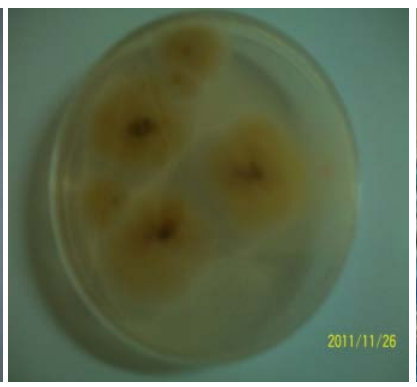

(f)

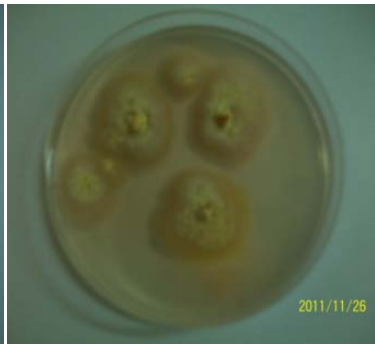

(c)

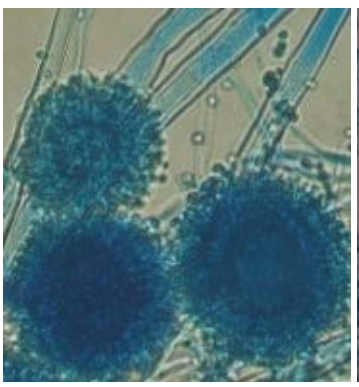

(g)

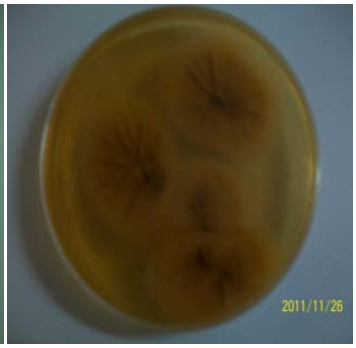

(d)

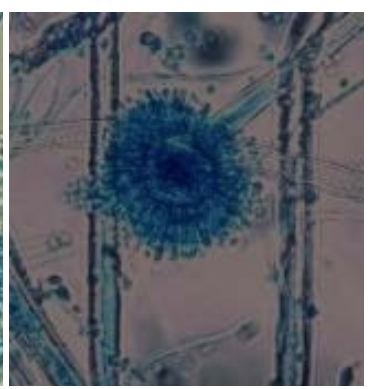

(h)

Figure 17. Aspergillus ostianus colonies on MEA (a \& d); CYA (b \& e); CZ (c \& f); (g) Biseriate conidia heads (e) the distinct globose vesicle.

conidia approximately 20 conidia after 7 days; colonies formed furrows on the media, produced exudates and orange yellow soluble pigments. Reverse colour was orange. On CZ the colonies were white cream when young to ochraceus with age and white mycelia; Reverse color was dark brown.

They were biseriate with radiate conidia heads; the conidia heads were very huge measuring 60 - $80 \mu \mathrm{m}$ in diameter with compact conidia; the vesicle was globose measuring 26 - 45 (65) $\mu \mathrm{m}$ in diameter. Stipe measured $500-1600 \times 8-12 \mu \mathrm{m}$ with thick and rough walls that were brown. Conidia size ranged between 2.5 - $4 \mu \mathrm{m}$; globose; smooth to finely rough and orange in colour. The phialides covered the entire vesicle and part of the stipe producing chains of conidia. Diagnostic feature: Large conidia heads with compact conidia with a deep 
orange reverse colour of the colonies on CYA.

\section{2) Aspergillus ostianus (40216 BM 1 orange)}

Colony diameter at 7 days at $25^{\circ} \mathrm{C}$; MEA 33 - $45 \mathrm{~mm}$; CYA 38 - $50 \mathrm{~mm}$; CZ 20 - $30 \mathrm{~mm}$, PDA 10 - $13 \mathrm{~mm}$. On PDA the colony growth was restricted and they were yellow to orange in colour forming radiating furrows. They had smooth texture, white mycelia but lacked exudates and soluble pigments. Reverse colour was yellow to orange. Colonies on MEA were white to ochre or orange in colour with a smooth texture, Figure 17; formed a mat of mycelia under the colonies and at the edges. They produced colourless to brown exudates but no soluble pigments. A lot of conidia were produced and had brown colour on the reverse. On CYA colonies were ochraceus with a thick mass of white mycelia that was smooth to rough in texture. They produced little conidia, had sporulation rings with radiating furrows. They produced colourless exudates and red to brown soluble pigments. Reverse colour was brown at the centre and yellow to the edges. On CZ the colonies were yellow with a lot of thick white mycelia underneath. There was poor growth of the CZ. Reverse was cream to brown.

Conidia heads were globose with compact conidia. They were exclusively biseriate with a globose vesicle measuring 28 - $35 \mu \mathrm{m}$ in diameter; the phialides covered the entire vesicle and part of the stipe. The stipe had thick and rough walls, brown in colour measuring $440-760 \times 8-14 \mu \mathrm{m}$, Conidia size ranged between $4-5 \mu \mathrm{m}$, smooth, globose and orange in colour. Diagnostic feature; Produced a lot of compactly packed conidia surrounding the biseriate globose conidia head.

\subsubsection{Aspergillus Section Clavati}

Members of Aspergillus section Clavati were rare with four isolates having been recovered, three from the samples soil and one from maize kernels. The species identified were Aspergillus rhizopodus, A. clavatus and A. longivesica which are shown in Figures 18-20.

\section{1) Aspergillus rhizopodus (40021 BS 14 grey)}

Colony diameters at $25^{\circ} \mathrm{C}$ for 7 days MEA; 54 - $60 \mathrm{~mm}$, CYA; 50 - $55 \mathrm{~mm}, \mathrm{CZ}$; 55 - $60 \mathrm{~mm}$. On MEA the colonies were dark green with rough and club shaped conidia heads attached to a short conidiophores. Mycelia were white, presence of exudates, lacked soluble pigments and sclerotia. Reverse was beige. The colonies had irregular edges, dark cream towards the centre and light cream at the edges on CYA. They produced small conidia heads. Exudates were present but lacked soluble pigments and sclerotia. Reverse was dirty brown. On CZ the colonies were clay pink in colour with irregular edges forming sporulation rings with age. The mycelia were colourless, had exudates and no soluble pigment. The colonies had conspicous aerial conidiophores onto which the conidia heads were attached. Reverse was dark tan as shown in Figure 18.

There were two types of conidia heads; short columnar $80-169 \mu \mathrm{m}$ and long clavate $240-245 \mu \mathrm{m}$; Two types of vesicle diameters, $72-160 \times 32-43 \mu \mathrm{m}$ and $230-250 \times 53-89 \mu \mathrm{m}$ clavate respectively. The stipe were also of two types measuring 756 - $1930 \times 22$ - $37 \mu \mathrm{m}$ and $322-563 \times 15-21 \mu \mathrm{m}$ smooth and colourless; Conidia size and shape; 1.6 - $3.2 \mu \mathrm{m}$ globose, smooth and green in colour. Diagnostic feature; had varied foot cells with finger like projections.

\section{2) Aspergillus clavatus (40038 BS 108 grey)}

Colony diameters after 7 days at $25^{\circ} \mathrm{C}$ were; MEA 35 - $40 \mathrm{~mm}$, CYA 34 - $40 \mathrm{~mm}$, CZ 28 - $32 \mathrm{~mm}$. On MEA the colonies were dull green to greyish turquoise with white mycelia round the colony at the periphery. The conidia heads were big clavate in shape and split into columns with age. Had no soluble pigments but produced colourless exudates. Reverse colour was brown. On CYA colonies were dull cream at the centre and white at the edges. They produced orange to brown exudates yellow soluble pigments. The mycelia were white with yellow colour on the reverse. The colonies on CZ were brown with irregular edges. Conidia heads were conspicuous and attached to long hyphal threads. Mycelia were white with velvet appearance and produced colourless exudates. Reverse was brown to dark tan, Figure 19.

They were uniseriate with radiate conidia heads. The vesicles were clavate and measured $32-40 \mu \mathrm{m}$ in diameter. The small vesicle was pyriform measuring $13-42 \mu \mathrm{m}$. The conidiophores were expanding toward the tip and measured $485-821 \times 16-35 \mu \mathrm{m}$, smooth and uncoloured to slightly brown in colour. The conidia were ellipsoidal, smooth and green measuring 3 - $5 \mu \mathrm{m}$ in size. Diagnostic feature: Had two types of conidia heads, with closely packed phialides.

\section{3) Aspergillus longivesica ( 40035 BS 110 green)}

Colony diameter at 7 days incubated at $25^{\circ} \mathrm{C}$; MEA 30 - $40 \mathrm{~mm}$; CYA 30 - $35 \mathrm{~mm}$; CZ 26 - $30 \mathrm{~mm}$. On PDA the colonies were green to grey with colourless mycelia forming furrows and sporulation rings. There was 


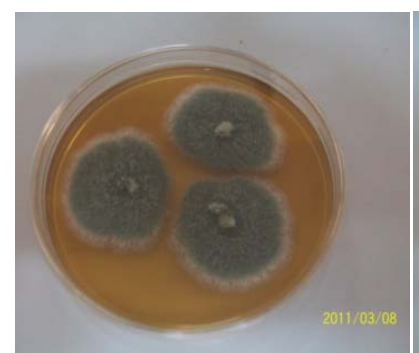

(a)

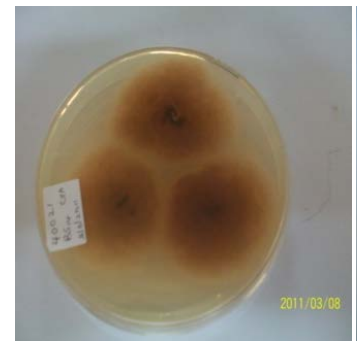

(e)

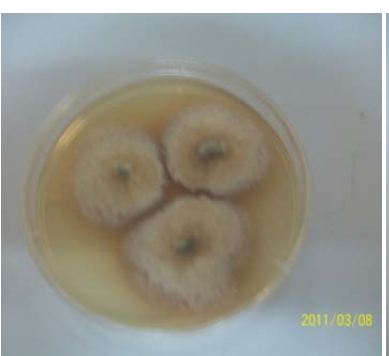

(b)

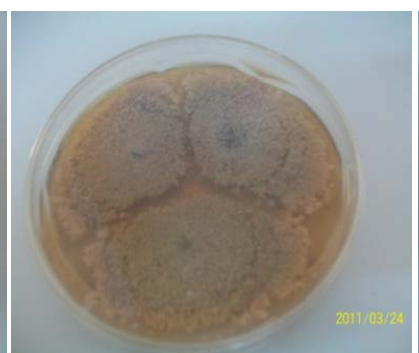

(c)

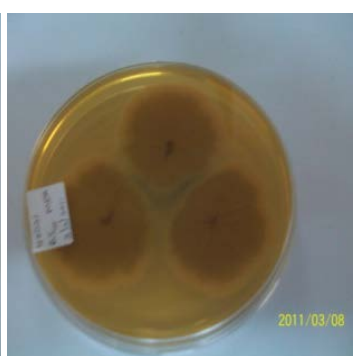

(d)

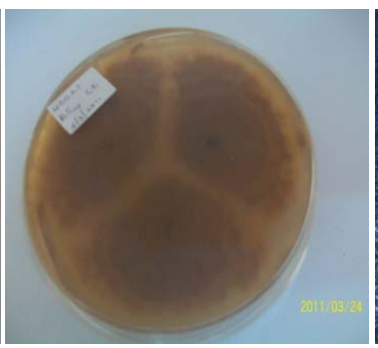

(f)

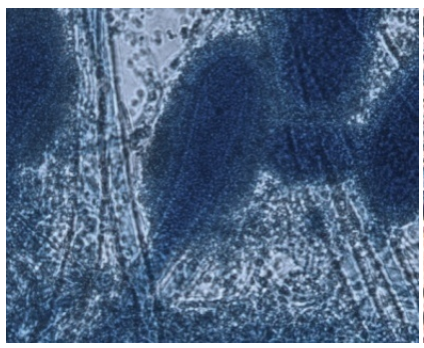

(g)

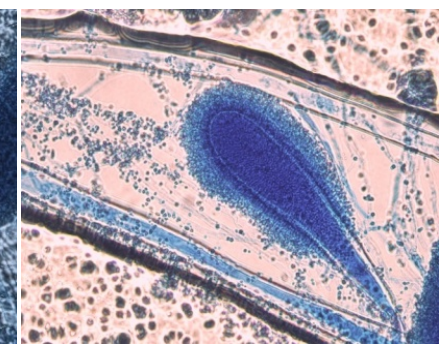

(h)

Figure 18. Aspergillus rhizopodus colonies on MEA (a \& d); CYA (b \& e); CZ (c \& f); (g \& h) uniserite conidia heads and clavate vesicle.

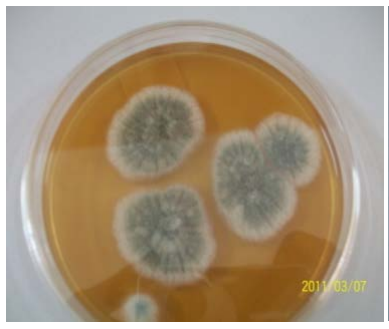

(a)

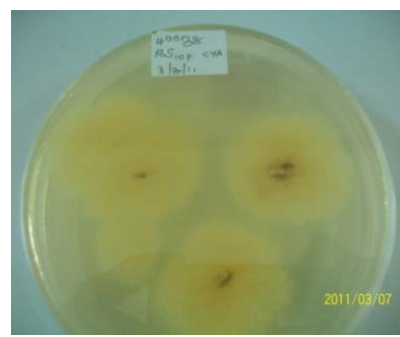

(e)

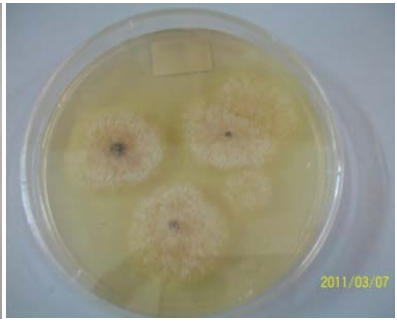

(b)

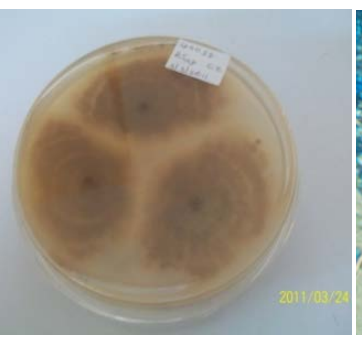

(f)

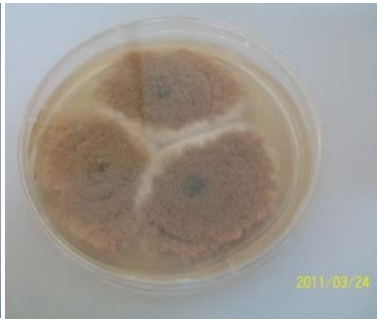

(c)

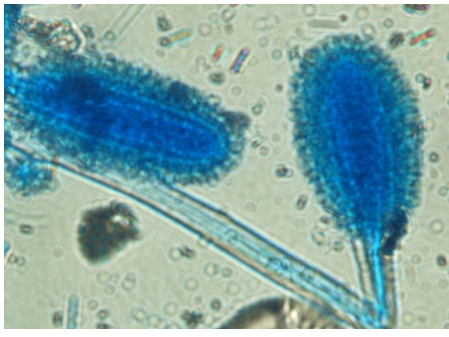

(g)

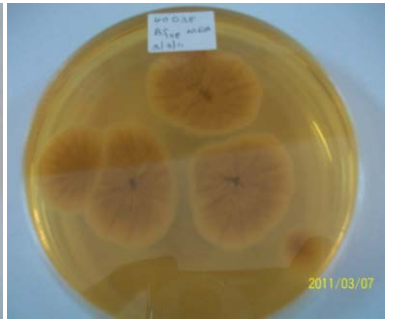

(d)

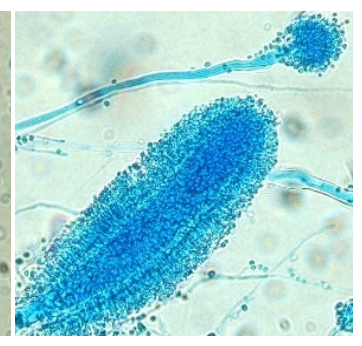

(h)

Figure 19. Aspergillus clavatus colonies on MEA (a \& d); CYA (b \& e); CZ (c \& f); (g) radiate conidia heads; (i) clavate and semi clavate vesicle.

presence of exudates but no soluble pigments. Conidia heads split into columns with age that gave the colonies a rough texture. Reverse colour was light dark tan. Colonies on MEA were in shades of greyish green with velvet texture, rough with white mycelia and irregular edges. They produced colourless exudates. Reverse was deep brown to indigo. On CYA the colonies were cream to slightly grey with white mycelia at the edges which were irregular. Formed furrows, produced colourless exudates but no soluble pigments. Reverse colour was brown to cream. The colonies on CZ were in shades of cream to greenish towards the centre with white mycelia seen at the edges. A lot of white mycelia produced under the colony with scattered conidia at the edges. Reverse colour was dark tan.

They were uniseriate having elongated conidia heads that split with age into columns. The vesicle were clavate in shape measuring (140) $200-300(320) \times 24$ - $53 \mu$ m. Stipe measured (720) $1440-1600(2000) \times 24-35$ 
(40) $\mu \mathrm{m}$ with thick walls, smooth and colourless. Conidia size ranged between 4.2 - $16 \times 2.8$ - $7 \mu \mathrm{m}$, elliptical to pyriform and green in colour. Diagnostic feature: Produced very wide stipe (Figure 20).

\subsubsection{Aspergillus Section Nidulantes}

One species of Aspergillus section Nidulantes was isolated from the soil maize fields of Kaptumo location and this was Aspergillus nidulans.

\section{Aspergillus nidulans (40034 BS 53 green)}

Colony diameters after 7 days of incubation at $25^{\circ} \mathrm{C}$ were; MEA 45 - $55 \mathrm{~mm}$; CYA 40 - $50 \mathrm{~mm}$. Colonies on MEA were dark green had white mycelia, abundant conidia and dark brown colour on the reverse. The colony morphology resembled on CYA and CZ with deep green colour, had white mycelia, and produced brown exudates with pink soluble pigments in the media. Reverse was brown.

Conidia heads were exclusively columnar and biseriate; the metulae covered only the upper part of the vesicle; had few philaides which were loosely attached on the small spathulate to pyriform vesicle; with a diameter of (8) 10 - $16 \mu \mathrm{m}$; Had very short conidiophores ranging from 40 - $144 \times$ (3) 4 - 6 (8) $\mu \mathrm{m}$; smooth walled and turned brown with age; Conidia size ranged between $3-4 \mu \mathrm{m}$, green; spherical with smooth to slightly rough walls. Diagnostic feature; had very short conidiophores and small vesicle (Figure 21).

\subsubsection{Aspergillus Section Candidi}

Aspergillus section Candidi was a rare group with only one isolate Aspergillus candidus was recovered from the soil.

\section{Aspergillus candidus (40034 BS 53 white)}

Colony diameter after 7 days of incubation at $25^{\circ} \mathrm{C}$; MEA 32 - $40 \mathrm{~mm}$; CYA 34 - $40 \mathrm{~mm}$; CZ 30 - $35 \mathrm{~mm}$; On PDA the colonies were white with colourless mycelia and straw colour on reverse. The colonies on MEA were white to cream at the centre, with a smooth texture and colourless mycelia. They produced exudates and soluble pigments. Reverse was brown. On CYA and CZ the colonies were white with a smooth texture and colourless mycelia although there was presence of exudates but no soluble pigments CZ. Reverse was cream.

Predominantly they were biseriate but some were uniseriate. Conidia heads were radiate with loosely packed phialides, the vesicles were sub globose to globose measuring (16) 18 - 30 (35) $\mu \mathrm{m}$ in diameter; the stipe meas ured $320-800 \times 5-10 \mu \mathrm{m}$, they had smooth and thick walls. Conidia sizes ranged between $2-3 \mu \mathrm{m}$; globose, smooth and green in colour. Diagnostic feature; had very small conidia, presence of diminutive vesicle as shown in Figure 22.

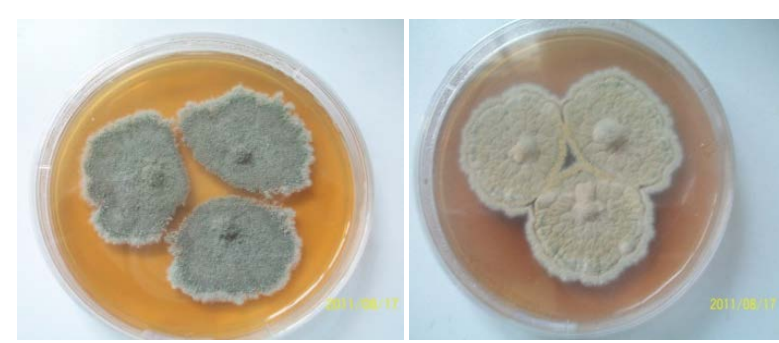

(a)

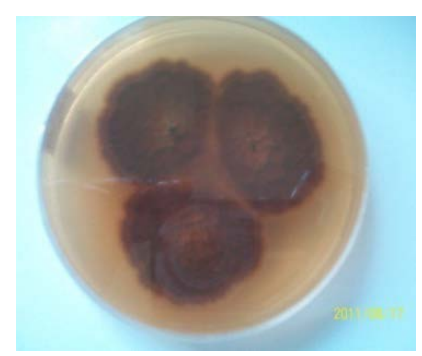

(e)

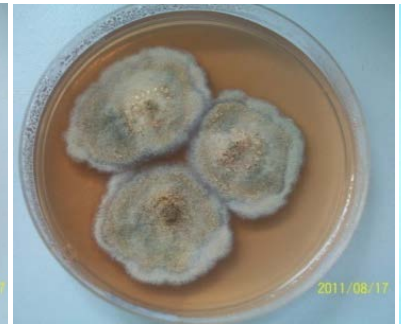

(c)

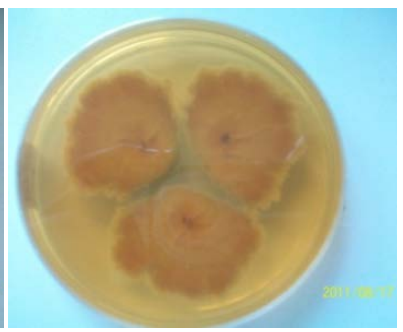

(d)

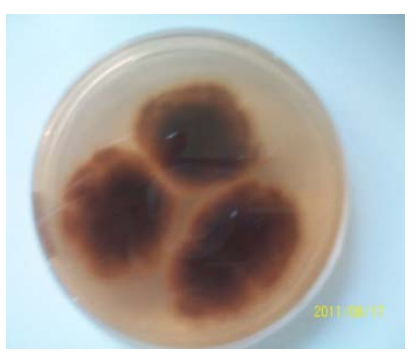

(f)

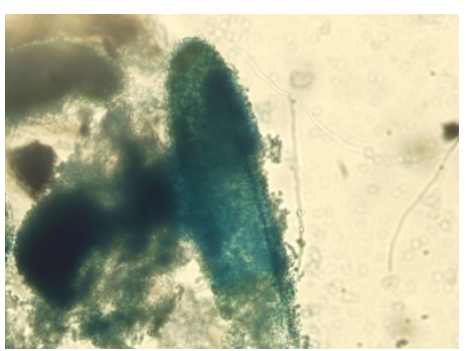

(g)

Figure 20. Aspergillus longivesica colonies on MEA (a \& d); CYA (b \& e); CZ (c \& f); (g) the clavate vesicle and radiate conidia head. 


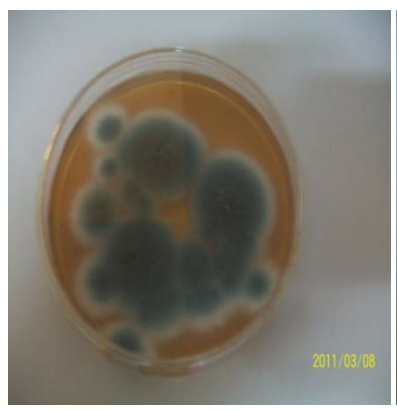

(a)

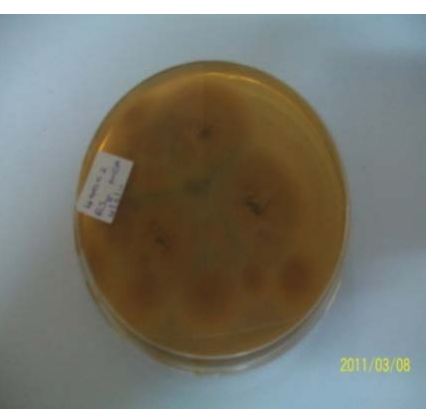

(b)

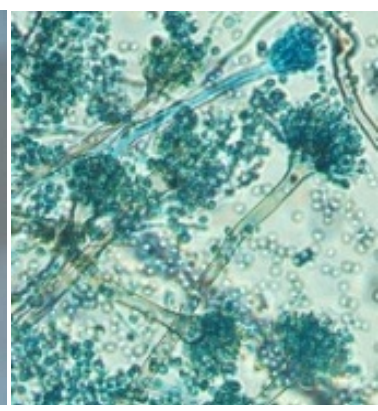

(c)

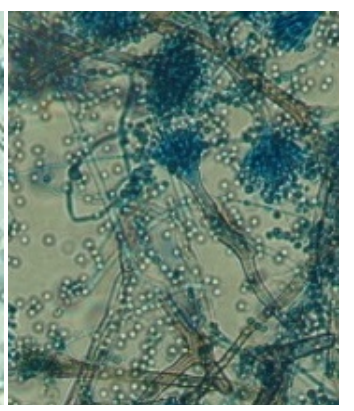

(d)

Figure 21. Aspergillus nidulans colonies on MEA (a \& b); (c) biseriate long columnar conidia heads; (d) brown and short conidiophores.

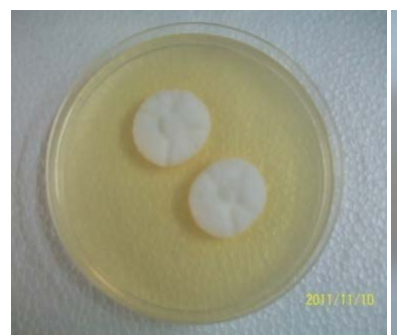

(a)

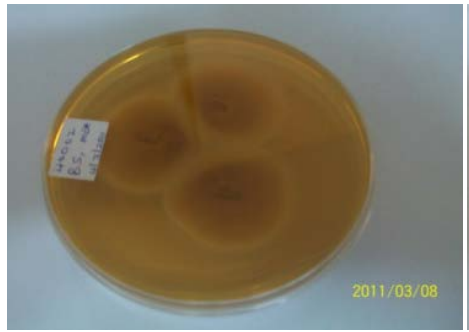

(e)

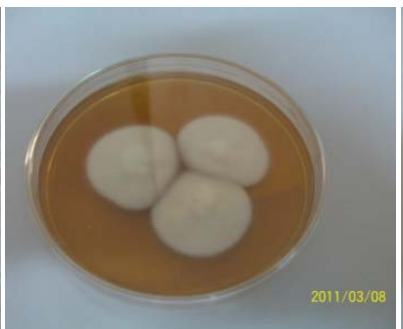

(b)

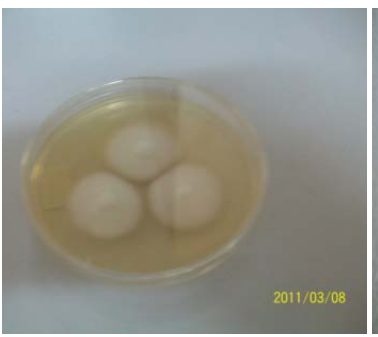

(c)

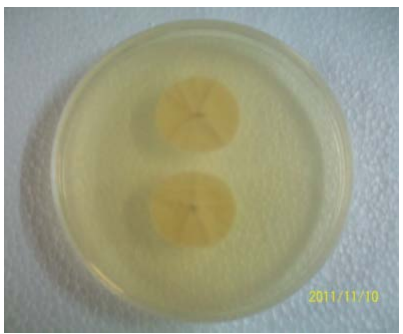

(d)

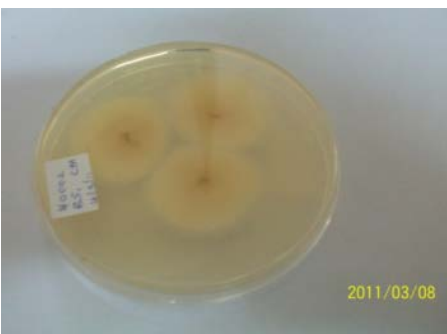

(f)

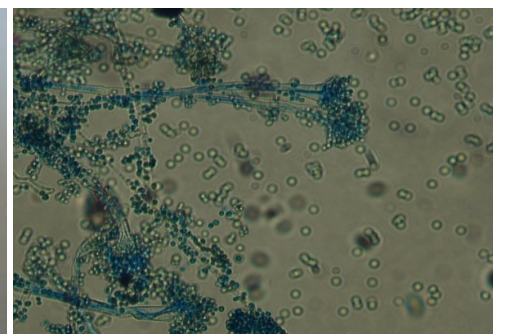

(g)

Figure 22. Aspergillus candidus colonies on PDA (a \& d); MEA (b \& e); CYA (c \& f); (g) conidiophores, conidia heads and conidia.

Table 1 shows the macro and micro morphological characteristics of Aspergillus isolated and identified from Nandi County of the Rift Valley, Kenya.

\section{Identification Key for Aspergillus Isolates from Nandi County}

1. Isolates were predominantly Biseriate$-2$

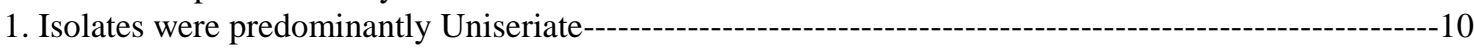

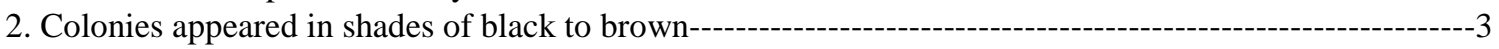

2. Colonies in shades of white, dark green, olivaceous brown to Ochraceous------------------------------6

3. Colonies had irregular edges on MEA with small vesicle less than $16 \mu \mathrm{m}------------------A$. Heteromorphus

3. Colonies with smooth edges on MEA with large vesicle between 32 - $60 \mu \mathrm{m}$----------------------------4

4. Colony diameter on CYA25 ${ }^{\circ} \mathrm{C}$ after 7 days was above $63 \mathrm{~mm}$ with large conidia size 7 - $10 \mu \mathrm{m}$

$$
\text { Diameter of the colonies on CYA } 25^{\circ} \mathrm{C} \text { was between } 45-55 \mathrm{~mm} \text { and conidia range of } 3
$$

5 . They had distinct sporulation rings on PDA with white mycelium at the edges on MEA and conidiation area black and has a narrow stipe-

A. brasiliensis

5. Colonies formed radial furrows on PDA, had small white edge of the colony on MEA and a large black area of conidiationA. niger

6. The conidia head was columnar with loosely packed phialides which covered half of the vesicle, had very short conidiophore that became brown withA. nidulantes 
Table 1. Macro and micro morphological characteristics of representatives of the Aspergillus species isolated from the maize kernels in Nandi County.

\begin{tabular}{|c|c|c|c|c|c|c|c|c|}
\hline Species & $\begin{array}{c}\text { Size (mm) } \\
\text { on MEA }\end{array}$ & Stipe Texture & Seriation & Vesicle Shape & $\begin{array}{c}\text { Vesicle } \\
\text { Diameter }(\mu \mathrm{m})\end{array}$ & $\begin{array}{c}\text { Conidia } \\
\text { Size }(\mu \mathrm{m})\end{array}$ & $\begin{array}{c}\text { Color, } \\
\text { Texture/Shape }\end{array}$ & $\begin{array}{c}\text { Conidia } \\
\text { Head/Shape }\end{array}$ \\
\hline A. parasiticus & $15-20$ & Smooth & $\mathrm{u} / \mathrm{b}$ & $\mathrm{P} / \mathrm{G}$ & $24-30$ & $4-5.8$ & $\mathrm{yg} / \mathrm{r} / \mathrm{G}$ & Radiate \\
\hline A. parasiticus & $30-60$ & Rough & $\mathrm{u} / \mathrm{b}$ & $\mathrm{P} / \mathrm{G}$ & $19-35$ & $3-7$ & $g / r / G$ & Radiate \\
\hline A. tamarii & $45-55$ & Rough & $\mathrm{b}$ & G & $26-43$ & $3-5$ & $\mathrm{~g} / \mathrm{G}$ & Radiate \\
\hline A. flavus & $50-55$ & Rough & $\mathrm{u} / \mathrm{b}$ & $\mathrm{R}$ & $18-36$ & $3.5-5$ & $\mathrm{yg} / \mathrm{r} / \mathrm{G}$ & Radiate \\
\hline A. duricaulis & $30-60$ & Smooth & $\mathrm{u}$ & P to Clab & $10-26$ & $2-3.5$ & $g / r / G$ & $\mathrm{~S} / \mathrm{C}$ \\
\hline A. fumigatus & $24-40$ & Smooth & $\mathrm{u}$ & Spathulate to Clavate & $19-31$ & $2-3$ & $\mathrm{~g} / \mathrm{r} / \mathrm{G}$ & $\mathrm{S} / \mathrm{C}$ \\
\hline A. novofumigatus (A) & $25-30$ & Smooth & U & $\mathrm{P} / \mathrm{R}$ & $21-29$ & $4-7$ & $\mathrm{~g} / \mathrm{s} / \mathrm{G}$ & $\mathrm{L} / \mathrm{C}$ \\
\hline A. novofumigatus $(B)$ & $40-50$ & Smooth & $\mathrm{U}$ & $\mathrm{P} / \mathrm{R}$ & $11-21$ & $3-5$ & $\mathrm{~g} / \mathrm{r} / \mathrm{G}$ & $\mathrm{L} / \mathrm{C}$ \\
\hline A. heteromorphus & $35-45$ & Rough & $\mathrm{b}$ & $\mathrm{S} / \mathrm{G}$ & $12-16$ & $3.5-4$ & $\mathrm{~b} / \mathrm{r} / \mathrm{G}$ & $\mathrm{S} / \mathrm{G}$ to $\mathrm{G}$ \\
\hline A. carbonarius & $40-60$ & Smooth & B & Umbrella Shaped & $41-60$ & $6-10$ & $\mathrm{~b} / \mathrm{r} / \mathrm{G}$ & $\mathrm{S} / \mathrm{G}$ to $\mathrm{G}$ \\
\hline A. aculeatus $(A)$ & $37-49$ & Smooth & $\mathrm{U}$ & $\mathrm{G} / \mathrm{S}$ & $48-74$ & $4-5$ & $\mathrm{~b} / \mathrm{r} / \mathrm{G}$ & G \\
\hline A. aculeatus (B) & $50-60$ & Smooth & U & G & $45-73$ & $4-5$ & $\mathrm{~b} / \mathrm{r} / \mathrm{G}$ & G \\
\hline A. niger & $45-55$ & Smooth & B & $\mathrm{S} / \mathrm{G}$ & $37-52$ & $4-6$ & $\mathrm{~b} / \mathrm{r} / \mathrm{G}$ & G \\
\hline A. japonicus & $45-50$ & Smooth & $\mathrm{U}$ & G/Elliptical & $29-45$ & $3-5$ & $\mathrm{~b} / \mathrm{s} / \mathrm{G}$ & Radiate \\
\hline A. brasiliensis & $45-50$ & Smooth & B & $\mathrm{P}$ & $32-38$ & $3-4.5$ & $\mathrm{~b} / \mathrm{r}$ & G \\
\hline A. ochraceaus & $25-30$ & Rough & $\mathrm{b} / \mathrm{u}$ & G & $26-55$ & $2.5-4$ & $\mathrm{o} / \mathrm{s} / \mathrm{G}$ & Radiate \\
\hline A. ostians & $33-45$ & Rough & B & G & $28-35$ & $4-5$ & $\mathrm{o} / \mathrm{s} / \mathrm{G}$ & G \\
\hline A. rhizopodus & $54-60$ & Rough & $\mathrm{U}$ & Clavate & $32-43$ & $1.6-3.2$ & $\mathrm{~g} / \mathrm{s} / \mathrm{G}$ & $\mathrm{S} / \mathrm{C}$ \\
\hline A. clavatus & $35-40$ & Smooth & $\mathrm{U}$ & $\mathrm{R} /$ Clavate & $32-40$ & $3-5$ & $\mathrm{~g} / \mathrm{s} / \mathrm{E}$ & Radiate \\
\hline A. longivesica & $30-40$ & Smooth & $\mathrm{U}$ & Clavate & $24-53$ & $3.8-6$ & $\mathrm{~g} / \mathrm{E}$ & Elongate \\
\hline A. nidulans & $45-55$ & Smooth & B & Spathulate/P & $9-16$ & $3-4$ & $\mathrm{~g} / \mathrm{s} / \mathrm{S}$ & $\mathrm{L} / \mathrm{C}$ \\
\hline A. candidus & $32-40$ & Smooth & $\mathrm{u}$ & SG/G & $17-30$ & $2-3$ & $\mathrm{w} / \mathrm{s} / \mathrm{G}$ & Radiate \\
\hline
\end{tabular}

The size of the colonies is after 7 days of incubation; Seriation; $\mathrm{u}=$ Uiseriate, $\mathrm{b}=$ Biseriate; Vesicle Shape; $\mathrm{P}=\mathrm{Pyriform}, \mathrm{G}=\mathrm{Globose}, \mathrm{R}=\mathrm{Radiate}$, Conidia Colour, Texture Shape; $y g=$ Yellow Green, $g=$ Green $b=$ Brown, Orange, $w=$ White, Rough, $\mathrm{s}=\mathrm{Smooth}, \mathrm{G}=\mathrm{Globose}, \mathrm{E}=\mathrm{Elliptical}, \mathrm{S}=$ Spherical, $\mathrm{S} / \mathrm{C}=$ Short Columnar, $\mathrm{L} / \mathrm{C}=$ Long Columnar, $\mathrm{S} / \mathrm{G}=$ Subglobose. The key below gives the morphological characteristics used to identify Aspergillus species together with the summary in Table 1.

6. The conidia heads were globose to radiate with phialides covering the entire or three quarter of the vesicle-

7. Conidia heads were large $(60$ - $80 \mu \mathrm{m})$ with compact phialides and conidia, they produced orange soluble pigments on CYA, making the reverse to have a deep orange colour and very small condia 2 - $4 \mu \mathrm{m}$ -A. ochraceous

7. Conidia heads were small (64 - $69 \mu \mathrm{m})$ and long stipe, the conidia were compact with white, brown to cinnamon colours on MEA

8. They showed fast growth on all the media, had large conidia with rough texture of the colonies on CYA and

$\mathrm{CZ}$ it was rough with conidiation area appearing yolk yellow -A. tamarii

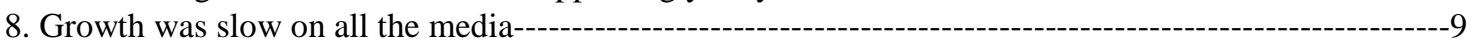

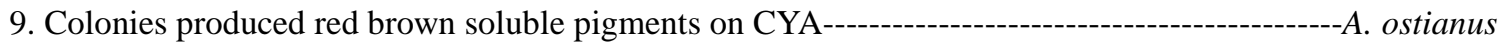

9. Produced colonies with white with small conidia 2 - $3 \mu \mathrm{m}$ smooth and white, there was presence of a diminuitive conidia head A. candidus 
10. Condia head were clavate-------_---11

10. Conidia head globose, radiate or columnar----o-

11. Colonies had irregular edges on MEA with very long with wide stipe and elliptical grey conidia

11. Colonies had regular edges on MEA, with moderate length and width of the stipe and ellipsoidal conidia that was blue grey-

12. The colonies had white edges of mycelium, with blue-grey appearance, formed radial furrows and sporulation rings on MEA, on CZ also formed sporulation rings and had two types of conidia heads

A. clavatus

12. The colonies were dark green with a very thin edge of white mycelium on MEA, had varied foot cells forming fingerlike projections -A. rhizopodus

13. The colonies were coffee brown on MEA and cocoa brown on CYA, they formed distinct radial furrows, had globose and ellipsoidal conidia heads with vesicle diameter ranging between 29 - $45 \mu \mathrm{m}$

13. The colonies were in shades of black and green----------------------------------------------------14

14. The colonies were black and date brown on MEA and showed they first growth on all the media with the colony diameter ranging between 38 - $60 \mathrm{~mm}$, they had very wide vesicle with diameters of 45 - $74 \mu \mathrm{m}$

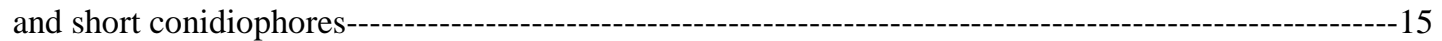

14. The colonies were yellow green to dark green with abundant conidation on sporulation on all the media$-16$

15. They had very first growth of the colonies on all the media and coffee brown in colour with radial furrows on CYA and cocoa brown in colour on CZ and dirty brown reverseA. aculeatus (A) 15. They showed slow growth on all the media, the colonies were light yellow on CYA and CZ. Produced lemon Yellow soluble pigments on CYA and formed with radial furrows both on the front and reverse of the colonies Reverse was deep yellowA. aculeatus (B)

16. Colonies appeared in shades of yellow green as they formed sporulation rings with white mycelia on MEA colonies on CYA and CZ were yellow with smooth to finely rough conidia (3.5 - $5 \mu \mathrm{m})--------$ A. flavus

16. Colony growth was restricted on CZ, they produced sclerotia on CYA and CZ, produced with rough and green conidia---------------------------------------------------------------------------------------17

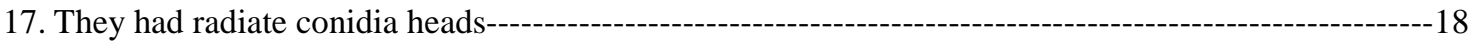

17. They had columnar conidia heads--

18. On PDA the colonies were dark green with distinct sporulation rings, some had knodding conidia heads, with pyriform to globose vesicle -----------------------------------------A. parasiticus (A)

18. The colonies had distinct alternate sporulation rings on PDA, conidia heads were upright at the end of the stipe and vesicle was radiate to globose--------------------------------A. parasiticus (B)

19. They produced soluble pigments on CYA, had pyriform to sub clavate to clavate vesicle short conidia

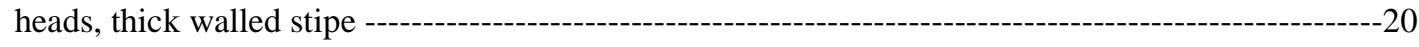

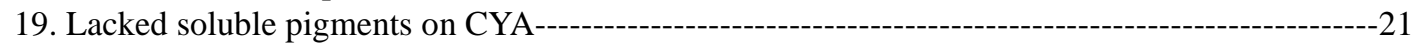

20. The vesicle was pyriform to sub clavate with a thick walled stipe and small conidia between 2 - 3.5 $\mu \mathrm{m}---\mathrm{-}$

20. The vesicle was spatulate to clavate, with very short conidiophores and the stipe expanded towards the tip as it joins the vesicle-

-A. fumigatus

21. They have varied shapes of the vesicles and the attachment of the phialides on the vesicle-----------22

21. Had large conidia 4 - $7 \mu \mathrm{m}$ with varied neck on stipe, some stipe expanded towards the vesicle others retained the same width, large vesicle 21 - $29 \mu \mathrm{m}$ phialides loosely attached onto the vesicle

-A. novofumigatus (A)

22. Had small conidia 3 - $5 \mu \mathrm{m}$, small vesicle 11 - $21 \mu \mathrm{m}$, phialides compactly packed and covered nearly half of the vesicle-A. novofumigatus (B)

\section{Discussion}

The results of the study indicated a high incidence of Aspergillus species from the soils of maize fields in Nandi. In previous study by [18] similar observations were reported on Aspergillus species. The high incidence of As- 
pergillus section Flavi mainly Aspergillus flavus and Aspergillus parasiticus were the common species in the three locations of Nandi. It was an indication of wide distribution in the soils which poses a high risk of dissemination of the fungi to the field crops by wind. In the previous studies by [13] in soils of maize fields in Nigeria and [19] in Illunois fields reported similar results. Contrary in a study carried out by [20] low levels of Aspergillus section Flavi in Iowa found during a non-epidermic years. The significance of high incidence of Aspergillus section Flavi is in regard to their aflatoxin production profiles and crop contamination in favourable conditions. Aspergillus had a high incidence of isolation from the maize grains followed by Fusarium, Penicillium and Alternaria were also part of the internal mycoflora. This poses the risk of multi-mycotoxin contamination by the formation of Penicillium and Alternaria toxins. Similar results were reported by [21] in Niger state in Nigeria where the fungi were isolated from maize samples during the harmattan season. In Kogi State of Nigeria [22], reported Fusarium being the most prevalent fungal species isolated from maize than Aspergillus and Penicillium.

Aspergillus, specifically section Flavi, was the main contaminant of maize in storage. This was followed by section Nigri. The most frequently isolated species of Aspergillus section Flavi was A. flavus, A. tamarii and A. parasiticus. Similar observations were reported by [22] reported similar results of Aspergillus species mainly $A$. flavus being the most common fungal contaminant of grains. The wide spread contamination of $A$. flavus showed the extent of pre-harveast and post-harvest contamination.

The high incidence of A. flavus in maize according to [23] [24] had a correlation with that found in the soil which is the primary inoculum of Aspergillus. The presence of high incidence of $A$. flavus in the samples is an indication that $A$. flavus is wide spread. This observation highlights the significant contribution made by farmers at household level to aflatoxin contamination in the maize value chain. Members of section Flavi isolated from the soil and maize kernels in Nandi that formed sclerotia all were of the L strain. Aspergillus L strains have been known to produce less aflatoxins that are less potent than the S strains that are more virulent and produce very high levels of aflatoxins toxins. Similar results have been reported by Similar observation was made by [13] in a study with soils of maize fields in Nigeria and [25] the work carried out in corn fields of Argentina. In conclusion morphological characteristics are the primary tools in the identification of various Aspergillus species; before delineating them into species using the other rapid technologies. Therefore the need to improve recognition of morphological characteristics of opportunistic Aspergillus species and also for common Aspergillus that can help rapid diagnosis in clinical set ups. This can be through training of more personnel to be able to use traditional tools that would be of help in areas where advanced technologies are absent or cannot be accessed.

\section{Conclusion and Recommendation}

In conclusion morphological characteristics are the primary tools in the identification of various Aspergillus species; before delineating them into species using the other rapid technologies. Therefore the need to improve recognition of morphological characteristics of opportunistic Aspergillus species and also for common Aspergillus that can help rapid diagnosis in clinical set ups. This can be through training of more personnel to be able to use traditional tools that would be of help in areas where advanced technologies are absent or cannot be accessed.

\section{Acknowledgements}

This work was part of the Safe Food Safe Dairy Project funded by the Finnish Ministry of Foreign Affairs. We also extend our gratitude to the University of Nairobi for availing the laboratories at Chiromo College.

\section{Conflict of Interest}

There is no conflict of interest from other co-others in the publication of this manuscript in this journal. All the co-others have contributed in the preparation of the manuscript up to the submission stage.

\section{References}

[1] Ainsworth, G.C. (1976) Introduction to the History of Mycology. Cambridge University Press, Cambridge. Alberts, A.W. (1998) Discovery, Biochemistry and Biology of Lovastatin. American Journal of Cardiology, 62, $10 \mathrm{~J}-15 \mathrm{~J}$. 
[2] McClenny, N. (2005) Laboratory Detection and Identification of Aspergillus Species by Microscopic Observation and Culture: The Traditional Approach. Journal of Medical Mycology, 43, S125-S128.

[3] Warris, A., Voss, A. and Verweij, P.E. (2001) Hospital Sources of Aspergillus: New Routes of Transmission. Journal Review in Microbiology, 18, 156-162.

[4] Guarro, J., Gene, J. and Stchigel, A.M. (1999) Development of Fungal Taxonomy. Clinical Microbiology Reviews, 12, 454-500.

[5] Bennett, J.W. (2010) An Overview of the Genus Aspergillus. In: Machida, M. and Gomi, K., Eds., Aspergillus: Molecular Biology and Genomics.

[6] Klich, M.A. (2002) Identification of Common Aspergillus Species. Centraal bureau voor Schim, Utrecht.

[7] Raper, K.B. and Fennel, D.I. (1965) The Genus Aspergillus. The Williams and Wilkins Company.

[8] Samson, R.A., Hoekstra, E.S. and Frisvad, J.C. (2004) Introduction to Food and Airborne Fungi. 7th Edition, Centraalbureau voor Schimmelcultures, Utrecht.

[9] Bennett, J.W. and Christensen, S.B. (1983) New Perspectives on Aflatoxin Biosynthesis. Advances in Applied Microbiology, 29, 53-92. http://dx.doi.org/10.1016/S0065-2164(08)70354-X

[10] Ministry of Finance and Planning Kenya (2002-2008).

[11] Okoth, S., Nyongesa, B., Ayugi, V., Kang'ethe, E., Korhonen, H. and Joutsjoki, V. (2012) Toxigenic Potential of Aspergillus Species Occuring on Maize Kernels from Two Agro-Ecological Zones in Kenya. Toxins, 4, 991-1007. http://dx.doi.org/10.3390/toxins4110991

[12] Traisat, H. (1989) Sampling, Sample Handling and Preparation in Grains and Cereals. In: Semple, R.L., Frio, A.S., Hicks, P.A. and Lozare, J.V., Eds., Mycotoxin Prevention and Control in Food Grains, UNDP/FAO Regional Network Inter-Country Cooperation on Preharvest Technology and Quality Control of Food Grains (REGNET) and the ASEAN Grain Postharvest Programme, Bankok.

[13] Cotty, P.J. (1994) Comparison of Four Media for Isolation of A. flavus Group of Fungi. Mycopathologia, 125, 125-162.

[14] Klich, M.A. (2002) Biogeography of Aspergillus Species in Soil and Litter. Mycologia, 94, 21-27. http://dx.doi.org/10.2307/3761842

[15] Pitt, J.I., Hocking, A. and Glend, D. (1983) An Improved Medium for the Detection of Aspergillus flavus and A. parasiticus. Journal of Applied Bacteriology, 54, 109-114. http://dx.doi.org/10.1111/j.1365-2672.1983.tb01307.x

[16] Nelson, P.E., Tousson, T.A. and Marasas, W.F.O. (1983) Fusarium Species: An Illustrated Manual for Identification. Pennsylvania State University, University Park.

[17] Pitt, J.I. and Hocking, A.D. (1997) Fungi and Food Spoilage. 2nd Edition, Blackie, London.

[18] Muthomi, J.W., Njenga, L.N., Gathumbi, J.K. and Cheminingwa, N. (2009) The Occurrence of Aflatoxins in Maize and Distribution of Mycotoxin-Producing Fungi in Eastern Kenya. Plant Pathology Journal, 8, 113-119. http://dx.doi.org/10.3923/ppj.2009.113.119

[19] Wicklow, D.T., McAlpin, C.E. and Platis, C.E. (1998) Characterization of the Aspergillus flavus Population within an Illinois Maize Field. Mycological Research, 102, 263-268. http://dx.doi.org/10.1017/S0953756297004851

[20] McGee, D.C., Olanya, O.M., Hoyos, G.M. and Tiffany, L.H. (1996) Populations of Aspergillus flavus in the Iowa Cornfield Ecosystem in Years Not Favorable for Aflatoxin Contamination of Corn Grain. Plant Disease, 80, 742-746. http://dx.doi.org/10.1094/PD-80-0742

[21] Surajudeen, A.A., Makun, H.A., Anjorin, S.T., Moronfoye, B., Adejo, F.O., Afolabi, O.A., Fagbayibo, G.B., et al. (2010) Fungal and Aflotoxin Contamination of Some Human Food Commodities in Nigeria. African Journal of Food Science, 4, 127-135.

[22] Gao, J., Liu, Z. and Yu, J. (2007) Identification of Aspergillus Section Flavi in Maize in North Eastern China. Mycopathologia, 164, 91-95. http://dx.doi.org/10.1007/s11046-007-9029-4

[23] Dorner, J.W., Cole, R.J. and Blankenship, P.D. (1998) Effect of Inoculum Agents on Preharvest Aflatoxin Contamination of Peanuts. Biological Control, 12, 171-176. http://dx.doi.org/10.1006/bcon.1998.0634

[24] Horn, B.W., Greene, R.L. and Dorner, J.W. (1995) Effect of Corn and Peanut Cultivation on Soil Populations of Aspergillus flavus and A. parasiticus in Southwestern Georgia. Applied and Environmental Microbiology, 62, 2472-2475.

[25] Nesci, A. and Etcheverry, M. (2002) Aspergillus Section Flavi Populations from Field Maize in Argentina. Letters in Applied Microbiology, 34, 343-348. http://dx.doi.org/10.1046/j.1472-765X.2002.01094.x 


\section{Appendix}

\section{Composition of the Media}

Potato Dextrose Agar

Potato dextrose agar

1 litre of distilled water

Quarter Strength Potato Dextrose Agar

Potato dextrose broth (Difco)

$9.75 \mathrm{~g}$

Bacteriological agar

Lactic acid

$2 \mathrm{ml}$

1 litre of distilled water

Modified Rose Bengal Agar

Mycological peptone

$5.0 \mathrm{~g}(\mathrm{P} 1(\mathrm{a}))$

Glucose

$10.0 \mathrm{~g}$ (G5)

Di-Potassium hydrogen phosphate

$1.0 \mathrm{~g}$ (P37)

Magnesium sulphate

$0.5 \mathrm{~g}$ (M7)

Rose bengal

$0.05 \mathrm{~g}(\mathrm{R} 8)$

Chloramphenical

$0.1 \mathrm{~g}$ (Fridge)

Bacteriological agar

$15.5 \mathrm{~g}$ (a2)

1 litre of distilled water

Malt Extract Agar

Malt extract powder

Bacteriological agar

$20 \mathrm{~g}$ (M1)

Deionised water

$12 \mathrm{~g}(\mathrm{~A} 1)$

1 litre

Czapek Yeast Extract Agar

Sodium nitrate

$3 \mathrm{~g}$

Di-hydrogen potassium phosphate

$1.0 \mathrm{~g}$

Potassium chloride

$0.5 \mathrm{~g}$

Ferrous sulphate hydrated

$0.01 \mathrm{~g}$

Yeast extract

$0.5 \mathrm{~g}$

Sucrose

$30 \mathrm{~g}$

Agar (plain)

$15.0 \mathrm{~g}$

Distilled water

1 litre

Czapek Dox Agar

Sodium nitrate

$3 \mathrm{~g}$

Di-hydrogen potassium phosphate

Potassium chloride

$0.5 \mathrm{~g}$

Ferrous sulphate hydrated

$0.01 \mathrm{~g}$

Sucrose

$30 \mathrm{~g}$

Agar (plain)

$15.0 \mathrm{~g}$

Distilled water

1 litre

Aspergillus Flavus Parasiticus Agar

Yeast extract

Bacteriological peptone

$10 \mathrm{~g}$

Ferric ammonium citrate

$0.5 \mathrm{~g}$

Chloramphenical

$0.1 \mathrm{~g}$

Dichloran, stock solution $0.2 \%$ in ethanol

1 litre 
Agar

Distilled water

$\mathrm{pH}$

V-8 Juice

$\mathrm{V}-8$ juice

$\mathrm{CaCO}_{3}$

Bacteriological agar

Deionised water
$15.0 \mathrm{~g}$

1 litre

6.2

$175 \mathrm{ml}$

$3.5 \mathrm{~g}(\mathrm{C} 3)$

$17.5 \mathrm{~g}$

800 - $900 \mathrm{ml}$ 